\title{
Unilateral Phase-Out of Coal to Power in an Emissions Trading Scheme
}

\author{
Thomas Eichner $^{1} \cdot$ Rüdiger Pethig ${ }^{2}$
}

Accepted: 19 July 2021 / Published online: 24 August 2021

(c) The Author(s) 2021

\begin{abstract}
We investigate the displacement effects of unilateral phase-out-of-coal policies in a stylized two-country model with coal- and gas-fired electricity generation in an international emissions trading scheme. In the basic policy scenario, electricity markets are national and one country bans coal while the emissions cap remains unchanged. The allocative displacement effects are strongly asymmetric: the coal-banning country suffers a welfare loss, the other country is better off, and aggregate welfare declines. Furthermore, the permit price decreases, while the electricity price rises in the unilaterally acting country and declines in the other country. If all countries would phase out coal, the effects would be symmetric and all countries would lose. We then extend the analysis to the cases (i) when the unilateral coal ban is combined with a moderate cut of the emissions cap (as recently suggested in an EU Directive) and (ii) when we allow for international trade in electricity. Compared to the basic unilateral policy, in these cases, the total welfare costs tend to be smaller and some tend to be shifted from the unilaterally acting country to the other one.
\end{abstract}

Keywords Unilateral $\cdot$ Phase-out $\cdot$ Coal $\cdot$ Gas $\cdot$ Electricity $\cdot$ ETS

JEL classification $\mathrm{H} 22 \cdot \mathrm{Q} 37 \cdot \mathrm{Q} 48$

\section{Introduction}

To prevent carbon emissions from exceeding the carbon budget implied by the ambitious climate target of the Paris agreement, large deposits of fossil energy resources must remain untapped (McGlade and Ekins 2015). Coal deposits, in particular, need

Helpful comments from two anonymous referees are gratefully acknowledged. Any remaining errors are the authors' sole responsibility.

Thomas Eichner

thomas.eichner@fernuni-hagen.de

Rüdiger Pethig

pethig@vwl.wiwi.uni-siegen.de

1 Department of Economics, University of Hagen, Universitätsstr. 41, 58097 Hagen, Germany

2 Department of Economics, University of Siegen, Unteres Schloss 3, 57072 Siegen, Germany 
to be left in the ground, because these are the most emissions-intensive fossil energy resources. This view is supported by the IPCC (2018, p. 16) in their special report on "Global Warming of $1.5^{\circ} \mathrm{C}$ ", where they discuss four illustrative pathways of emissions reductions with different projected changes in primary energy from fossil energy resources in 2030 relative to 2010 . Averaged across these pathways, the change required in primary energy from coal, gas, and oil is about minus $71 \%$, plus $6 \%$, and plus $8 \%$, respectively.

To date, many countries have been producing a large share of their electricity from coal. In the $\mathrm{EU}$, about $15 \%$ of the fossil energy resources used for generating electricity are still coal resources (Agora Energiewende and Sandbag 2020, p. 10), and many EU citizens and environmental groups are concerned about their governments' reluctance regarding, or exessively slow pace of phasing out coal. Recently, the European Union adopted the so-called 'European Green Deal' (European Commission 2019) which contains a call for the rapid phase-out of coal. However, the impression we get from the intensive public discussion about phasing out coal-based electricity generation is that there are policymakers, media and even economists who lack a clear understanding of the impact of the phaseout policy when performed in an international ETS, such as the EU ETS, which is characterized by the interaction of climate policies at national levels and that of the EU. As is well-known, reducing emissions cost-effectively requires a uniform carbon price, and a well-designed ETS accomplishes that for the emissions covered by the ETS. However, if the ETS contains coal- and gas-fired power plants and coal is phased out by command and control, the (shadow) emissions price is no longer uniform. Our paper aims to identify the distortions that such second-best phase-out policies generate in the markets for electricity and permits, and to assess the resulting impact on the countries' welfare.

In a simple static two-country model, we analyze phase-out policies when electricity from coal and natural gas is generated under the umbrella of an ETS. Our crucial and indeed realistic assumption is that the costs of electricity from gas exceed those from coal and, that the emissions intensity of electricity from coal exceeds that from gas. Both countries are price takers on the markets for electricity and permits, and these markets clear both endogenously and simultaneously.

Our emphasis is on unilateral phase-out-of-coal policies that involve effects on both efficiency and distribution. In the basic policy scenario (Scenario 1) with national electricity markets, the emissions cap remains unchanged such that the ban of coal obviously has no effect on the level of climate change, because aggregate emissions are fixed. If emissions decrease in one country, they necessarily increase in the other country by the same amount. This so-called waterbed effect has been studied before in various settings and also occurs when coal is unilaterally phased out, but this is not at the center of our analysis. We focus on the policies' distortionary effects on prices, on demands and supplies and especially on the countries' welfare. To the best of our knowledge, these effects have not yet been rigorously analyzed. We determine their signs analytically and illustrate the equilibria of the markets for permits and electricity before and after the phase-out. The sum of consumer and producer rents is our indicator of consumption welfare that we use to determine the welfare changes induced by the policy.

It should not come as a surprise that the unilateral phase-out of coal in Scenario 1 reduces the consumption welfare of the group of ETS countries, as all phase-out policies do, because such policies imply non-uniform (shadow) emissions prices and therefore violate cost-effectiveness. Scenario 1 is shown to exhibit strong asymmetric distributional effects. The country that bans coal unilaterally suffers a welfare loss and the other country is better off. Furthermore, the electricity price rises in the unilaterally acting country 
and declines in the other country, and the permit price decreases, which is definitively the wrong price signal when high emissions cause excessive climate damage.

We seek to deepen insight into the effects of a unilateral ban of coal in Scenario 1 by modifying the analytical framework in two different ways. First we replace the strong assumption of a constant emissions cap by considering a policy that consists of a combination of unilateral coal phase-out and moderate tightening of the emissions cap (Scenario 2). Such a policy mix is suggested in a recent revision of the EU ETS Directive (Directive EU 2018/410) which provides coal banning countries with the option to cancel permits from their auction volume to prevent the decline in their permit demand from increasing the use of these permits in the other ETS countries. If a coal banning country makes use of the option provided in the directive, it essentially tightens the emissions cap of the EU ETS and thus implements a mixed policy that combines the phase-out of coal with some tightening of the cap. This policy mix (Scenario 2) turns out to reduce both climate damage and consumption welfare in both countries. When the emissions cap is fixed (Scenario 1), the signs of the other comparative-static effects are all different in the unilaterally acting country from those in the other countries. When the emissions cap is tightened (Scenario 2), the permit price increases and all other effects exhibit the same sign for all countries. These differences suggest that the distributional effects of a unilateral coal ban are much stronger in Scenario 1 than in Scenario 2.

Our second modification of the analytical framework is to replace the national electricity markets in Scenarios 1 and 2 with an international market for electricity. In Europe, there is some transboundary trade in electricity, but the cross-border infrastructure is inappropriate and price convergence is partial (European Commission 2017). Therefore, we replace the polar assumption of no trade with the opposite polar assumption of free trade and thus delineate the range of outcomes expected in semi-international electricity markets. In line with the familiar proposition that opening borders creates 'gains from trade', our results indicate that the trade in electricity has a smoothening effect and shifts to the other country a share of the welfare loss that accrues to the coal-banning country in Scenario 1.

Our paper is related to the literature that studies the impact of climate policies in the presence of different carbon sources, and to the environmental federalism literature. In closed economies, Chakravorty et al. (2008) and van der Ploeg and Withagen (2012) study the optimal extraction of different non-renewable resources in dynamic models with a ceiling and a carbon tax, respectively. Coulomb and Henriet (2018) elaborate the distributional impacts of optimal carbon taxation in a dynamic model with coal and gas.

Turning to environmental federalism, Oates and Schwab (1988) and Ogawa and Wilda$\sin$ (2009) show, in one-resource models with local and global pollution, ${ }^{1}$ respectively, that decentralized policymaking is efficient when countries are small and take market prices as given. Santore et al. (2001) introduce a federal ETS that overlaps with state-level emissions taxes, and point out that strategic permit-price manipulation of state-level regulators leads to an inefficient allocation. Finally, Verbon and Withagen (2010) elaborate that efficiency can be restored by an appropriate initial distribution of permits that exactly neutralizes the harmful permit-price manipulation.

In open economies, Fischer and Salant (2017) study different unilateral and global climate policies in a model with multiple resource pools with different extraction costs to keep the temperature increase below $2^{\circ} \mathrm{C}$. Daubanes et al. (2021) examine the strategy of

\footnotetext{
1 An appraisal of the early environmental federalism literature is provided by Cropper and Oates (1992).
} 
an open economy aimed at reducing its carbon emissions by replacing the consumption of coal with gas, and show that the country's unilateral emission reduction may ultimately increase global carbon emissions. Our paper also focusses on the unilateral substitution of coal with gas, but to the best of our knowledge, is the first to analyze the phase-out of coal by one country in an EU-type international ETS. When one country phases out coal, coalbased electricity may increase in other countries, and permits and emissions shift to the other countries. The former phenomenon is known as leakage and the latter as the waterbed effect. Leakage is well known in the context of carbon regulation (see e.g. Daubanes et al. 2017, Garella and Trentinaglia 2019 and Klaushal and Rosendahl 2020). Waterbed effects have recently received attention in studying the EU ETS (Perino 2018, Eichner and Pethig (2019a) and Pahle et al. 2019, Hamaguchi 2020). It is worth mentioning that the present paper focusses mainly on the substitution between coal and gas, whereas substitution between fossil fuels and a renewable resource in an EU ETS has been tackled by Jarke and Perino (2017) and Eichner and Pethig (2019a).

The rest of the paper is organized as follows. Section 2 sets up a stylized two-country model of electricity generation by means of natural gas and coal and $\mathrm{CO}_{2}$ regulation. Section 3 analyzes the allocative displacement effects in the basic unilateral phase-out-of-coal policy (Scenario 1) and compares it with all countries phasing out coal. Section 4 extends Scenario 1 in two directions: It first analyzes a policy that combines the unilateral phaseout of coal with a specific cut of the emissions cap (Scenario 2) and then reconsiders Scenarios 1 and 2 with the national electricity markets being replaced by a common international electricity market. Section 5 concludes.

\section{The Model: An International ETS with Generation of Electricity from Coal and Gas}

The Markets for Permits and Electricity. We consider a two-country economy, in which each country $i=A, B$ produces electricity in power plants fired either by coal ( $c$-electricity) or by natural gas ( $g$-electricity). The production of $y_{h i}$ units of $h$-electricity generates $e_{h}=v_{h} y_{h i}$ units of carbon emissions, $h=c, g, i=A, B$, where the emissions intensities satisfy $v_{c}>v_{g}>0$. That $c$-electricity is more emissions-intensive than $g$-electricity is a welldocumented empirical fact (MacKay and Stone 2013, p. 4ff., Daubanes et al. 2021). The difference between the emissions intensities turn out to be crucial for the effects of banning coal.

Carbon emissions from all electricity-generating sectors are regulated in an emissions trading scheme ${ }^{2}$ (ETS) that is jointly operated by countries $A$ and $B$. The emissions cap $\bar{e}>0$ puts an upper bound on total emissions and is assumed to be binding. In formal terms, the ETS constraint is given by

$$
v_{c}\left(y_{c A}+y_{c B}\right)+v_{g}\left(y_{g A}+y_{g B}\right)=\bar{e} .
$$

Electricity firms have to cover their emissions by emission allowances, simply referred to as permits, that are auctioned at price $q$. They take the electricity price $p_{i}$ and the permit price $q$ as given and maximize with respect to $y_{h i}$ the profit $\pi_{h i}=p_{i} y_{h i}-K^{h}\left(y_{h i}\right)-q v_{h} y_{h i}$,

\footnotetext{
${ }^{2}$ In practice, several industries producing electricity-intensive final goods are also covered by many ETSs, notably by the EU ETS.
} 
where $K^{h}\left(y_{h y}\right)$ are production costs satisfying ${ }^{3} K_{y_{i}}^{h}>0$ and $K_{y_{i} y_{i}}^{h}>0$. The first-order conditions $p_{i}-K_{y}^{h}-q v_{h}=0$ readily yield the electricity supply functions ${ }^{4}$

$$
y_{h i}=S^{h}\left(p_{i}, q\right) \quad \text { with } S_{p_{i}}^{h}>0 \text { and } S_{q}^{h}<0 \quad h=c, g ; i=A, B .
$$

The trade in electricity is assumed to be perfectly competitive as in Fischer and Preonas (2010) and Novan (2017). That is, the wholesale electricity prices are assumed to be fully and immediately passed through to retail consumers. The choice between modelling national electricity markets or a single international market is difficult, since it is unclear which of these assumptions is more realistic.

In practice electricity markets are very complex, not least with regard to their interconnectedness. Over the years, the EU stepped up its efforts to integrate formerly barely connected national electricity markets, and made progress through market coupling and investments in cross-border interconnections. Currently, electricity is traded among Member States with most exports and imports fluctuating "... in a narrow range of $10 \%$ of the total domestic generation" (European Commission 2017, p. 13). That speaks for assuming a single (perfectly competitive) electricity market. However, differences across Member States in wholesale and retail electricity prices across the EU are significant (European Commission 2017) and price convergence is only partial, not least because of inappropriate cross-border infrastructure, coordination and cooperation. These arguments point in the direction of national electricity markets.

To cope with the partially integrated empirical electricity markets, we will derive all results for national electricity markets in Sect. 3 and 4.1, and in Sect. 4.2 for an international electricity market. Accordingly, we now proceed with two national electricity markets with the equilibrium conditions

$$
y_{c i}+y_{g i}=x_{i} \quad i=A, B,
$$

where $x_{i}$ is the demand for electricity (of either kind) in country $i$. To complete the description of the model, we define the countries' electricity demand function

$$
x_{i}=D\left(p_{i}\right) \quad \text { with } D_{p_{i}}<0 \quad i=A, B .
$$

The equations in (1)-(4) contain nine equations that determine the nine endogenous variables $y_{c A}, y_{c B}, y_{g A}, y_{g B}, x_{A}, x_{B}, p_{A}, p_{B}$ and $q$. In its most compact form, this system of equations is reduced to the three market equilibrium conditions

$$
\begin{gathered}
S^{c}\left(p_{i}, q\right)+S^{g}\left(p_{i}, q\right)=D\left(p_{i}\right) \quad i=A, B, \\
v_{c}\left[S^{c}\left(p_{A}, q\right)+S^{c}\left(p_{B}, q\right)\right]+v_{g}\left[S^{g}\left(p_{A}, q\right)+S^{g}\left(p_{B}, q\right)\right]=\bar{e}
\end{gathered}
$$

which determine the prices $p_{A}, p_{B}$ and $q$. Since all three equilibrium conditions depend on the permit price $q$, the markets for electricity and the permit market are interdependent and therefore need to clear simultaneously. The well-known normative property of an equilibrium satisfying (5) and (6) is that the emissions cap is implemented at minimum cost (presupposing that it is less than the aggregate emissions in the laissez-faire economy).

\footnotetext{
${ }^{3}$ Upper-case letters represent functions and subscripts attached to them indicate partial derivatives.

${ }^{4}$ The properties of the function $S^{h}\left(p_{i}, q\right)$ are derived in Appendix A.
} 
In order to assess the impact of the phase-out-of-coal policies to be analyzed below, we define country $i$ 's welfare, $w_{i}$, as the difference between its consumption welfare, $u_{i}$, and climate damage, ${ }^{5,6} H(\bar{e})$,

$$
w_{i}=u_{i}-H(\bar{e})
$$

Consumption welfare $u_{i}$ consists of the sum of consumer surplus $\int_{0}^{x_{i}} P(z) \mathrm{d} z_{i}-p_{i} x_{i}+q\left(v_{c} y_{c i}+v_{g} y_{g i}\right)$ and producer surplus (= profits) $\pi_{c i}+\pi_{g i}$, where $P\left(x_{i}\right)$ is the inverse of the electricity demand function $D\left(p_{i}\right)$ from (4). Thus, consumption welfare is given by

$$
u_{i}=\int_{0}^{x_{i}} P(z) \mathrm{d} z_{i}-K^{c}\left(y_{c i}\right)-K^{g}\left(y_{g i}\right) \quad i=A, B .
$$

The allocative impact of changes in the emissions cap. In our investigation of phase-out policies in the next sections, we supplement the comparative-statics with graphical analyses of the allocative displacement effects in the markets for permits and electricity. It is therefore useful to prepare for this analysis by illustrating the joint market equilibria and their dependence on the size of the emissions cap. Exploiting symmetry, it is convenient to drop the subscripts $i, A$ and $B$ throughout in (5) and (6), which yields the simplified equilibrium conditions ${ }^{7}$

$$
S^{c}(p, q)+S^{g}(p, q)=D(p) \quad \text { and } \quad 2 v_{c} S^{c}(p, q)+2 v_{g} S^{g}(p, q)=\bar{e} .
$$

Suppose the prices $p_{0}$ and $q_{0}$ satisfy the two equations in (9) when the emissions cap $\bar{e}=\bar{e}_{0}$ is given. Then point $\mathcal{S}_{0}$ in the right-hand side panel of Fig. 1 illustrates the equilibrium in the electricity market if we make the assignments $C_{0} D_{0} \hat{=} S^{g}\left(p, q_{0}\right)$, $E_{0} F_{0} \hat{=} S^{c}\left(p, q_{0}\right)+S^{g}\left(p, q_{0}\right), G H \hat{=} D(p)$, (while disregarding the dashed curve $\left.E_{1} F_{1}\right)$. Next, we tighten the emissions cap from $\bar{e}_{0}$ to $\bar{e}_{1}<\bar{e}_{0}$ and describe the transition to the new joint equilibrium as follows. At the initial equilibrium prices $\left(p_{0}, q_{0}\right)$, the electricity markets are still in equilibrium, but the permit market now has excess demand. We leave $q$ unchanged and decrease $p$ until the supply of electricity has declined so much that the permit market equilibrium is restored. In Fig. 1, that change corresponds to a move from point $\mathcal{S}_{0}$ to point $\tilde{\mathcal{S}}$, and we denote the associated electricity generation by $y_{1}=\tilde{y}_{c}+\tilde{y}_{g}<y_{0}$. In order to eliminate the disequilibrium in the electricity market without disturbing the equilibrium in the permit market, we combine increases in $p$ with increases of $q$ such that the electricity supply $y_{1}$ remains unchanged. We continue changing the prices in that way until we reach $p_{1}>p_{0}$ and $q_{1}>q_{0}$, such that $S^{c}\left(p_{1}, q_{1}\right)+S^{g}\left(p_{1}, q_{1}\right)=y_{1}=x_{1}=D\left(p_{1}\right)$. In Fig. 1 , these price changes correspond to a move from point $\tilde{\mathcal{S}}$ to point $\mathcal{S}_{1}$. The aggregate electricity

\footnotetext{
${ }^{5}$ Burning natural gas and especially coal causes local air pollution in addition to climate damage. See e.g. Pittel and Rübbelke (2017), Holland et al. (2018) and Fell et al. (2019). For reasons of tractability, we do not consider such ancillary pollution damage.

${ }^{6}$ It is unnecessary to specify the properties of the damage function $H$. If the phase-out policy leaves the emissions cap $\bar{e}$ unchanged, the welfare change equals the change in consumption welfare; if that policy is combined with a change in the cap, the change in climate damage is the same in both countries.

7 We cannot make use of this simplification when we later analyze unilateral phase-out policies that create asymmetries between countries which have been assumed to be symmetric ex ante.
} 


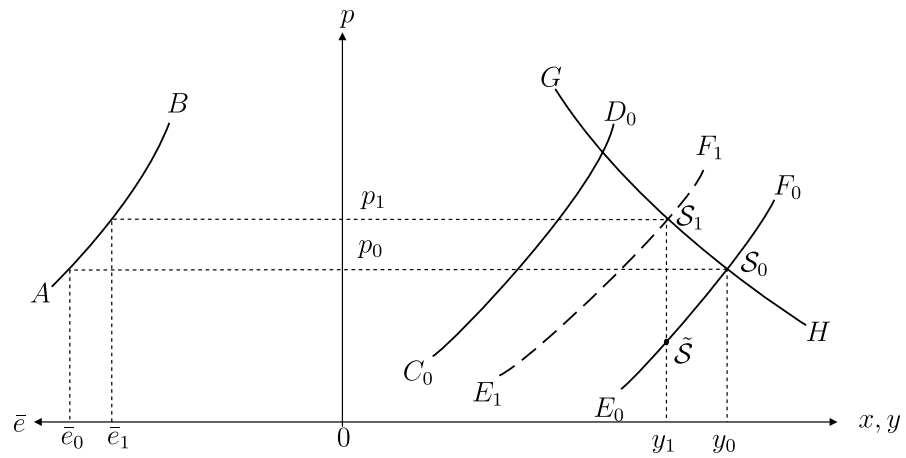

Fig. 1 Joint equilibrium of the markets for electricity and permits, depending on the size of the emissions cap

supply curve passing through the new equilibrium point $\mathcal{S}_{1}$ is given by the dashed curve $E_{1} F_{1} \hat{=} S^{c}\left(p_{1}, q_{1}\right)+S^{g}\left(p_{1}, q_{1}\right)$ so that equations (9) are satisfied in $\mathcal{S}_{1}$ for $\bar{e}=\bar{e}_{1}, p=p_{1}$ and $q=q_{1}$. The inverse relationship between the emissions cap and the equilibrium electricity price is proved in Appendix A and illustrated in the left-hand panel of Fig. 1. In sum, reducing the emissions cap increases the permit price, the increase then shifts the aggregate electricity supply curve to the left, and that shift increases the electricity price.

For the subsequent analysis of phase-out policies, it is useful to answer the question of how the mix of $c$ - and $g$-electricity will change if an initial lax emissions cap $\bar{e}_{0}$ is successively tightened. Since reducing the cap raises the permit price, and the emissions intensity of electricity is higher in the $c$ - than in the g-electricity sector, payments for emissions become higher in the former than in the latter. This makes $c$-electricity less competitive and we prove in Appendix A that the share of $g$-electricity in the electricity mix increases. It follows that there is an emissions cap $\tilde{\bar{e}}$ smaller than $\bar{e}_{0}$, such that no $c$-electricity is generated anymore, if $\bar{e}<\tilde{\bar{e}}$. Under these conditions that appear to be realistic, the cost-effective policy of phasing out coal in an ETS with an initial emissions cap $\bar{e}>\tilde{\bar{e}}$ is to reduce the cap from $\bar{e}$ to $\tilde{\bar{e}}$. As an implication, any phase-out of coal by regulation other than through tightening the cap is cost-ineffective. Our subsequent analysis seeks to specify the ineffectiveness of command-and-control phase-out policies with the focus on unilateral policies.

\section{Unilateral policy of phasing out coal}

A broad consensus among climate researchers is that the current mitigation effort is insufficient to achieve the Paris climate goal. The uniform worldwide carbon price (here in the form of a permit price) necessary for the cost-effective implementation of the Paris climate goal is estimated at about $65 \frac{€}{t \mathrm{CO}_{2}}$ by 2020 and rising to $85 \frac{€}{t \mathrm{CO}_{2}}$ by 2030 (Stiglitz and Stern 2017). In contrast, the permit price in the EU-ETS in November 2020 has been about $25 \frac{€}{t \mathrm{CO}_{2}}$. If the EU were to tighten the emissions cap so strongly that the permit price rises to $65 \frac{€}{t \mathrm{CO}_{2}}$ or even to $85 \frac{€}{t \mathrm{CO}_{2}}$, the generation of $c$-electricity would presumably be unprofitable and therefore be phased out, without further regulatory measures on the part of governments.

Policymakers correctly expect phasing out coal via tightening the emissions cap to increase the prices of electricity and permits. They prefer low prices via lax emissions 
Table 1 Allocative impact of country A's unilateral ban of coal (Scenario 1)

\begin{tabular}{lllllll}
\hline & & $\mathrm{d} y_{g A}$ & $\mathrm{~d} x_{A}=\mathrm{d} y_{A}$ & $\mathrm{~d} p_{A}$ & $\mathrm{~d} q$ & $\mathrm{~d} u_{A}$ \\
\hline $\mathrm{d} \bar{y}_{c A}<0$ & & + & $-\dagger$ & $+^{\dagger}$ & - & - \\
& $\mathrm{d} y_{c B}$ & $\mathrm{~d} y_{g B}$ & $\mathrm{~d} x_{B}=\mathrm{d} y_{B}$ & $\mathrm{~d} p_{B}$ & $\mathrm{~d} q$ & $\mathrm{~d} u_{B}$ \\
$\mathrm{~d} \bar{y}_{c A}<0$ & + & - & + & - & - & + \\
\hline
\end{tabular}

$\dagger$ holds if the function $K^{g}$ is quadratic and $v^{c}>2 v_{g}$

caps for political-economic reasons such as myopia or concern for low income groups that would be hit hard by high electricity prices ('energy poverty') or concern for industries that would face higher costs and become less competitive in the world market. Although concerned citizens and environmental groups are increasingly pressing for tougher climate policies, they do not necessarily endorse price-increasing policies either. Thus, a politically feasible compromise would be to keep the emissions cap lax and 'toughen' the climate policy by banning the generation of $c$-electricity via government directive or legislation. The questionable 'rationale' is that $c$-electricity is 'dirtier' than $g$-electricity and should therefore be phased out first. An interesting case in point is how the emissions cap of the EU-ETS has been set in the past. The center (EU Commission) lacked the necessary consent of the Member States to implement the cost-effective phase-out-of-coal policy, which is to tighten the cap as described at the end of the previous section. ${ }^{8}$ Some EU-countries, which would have favored a more stringent emissions cap, turned to making plans - or have already taken action - to phase out the generation of $c$-electricity in a command and control fashion.

In what follows, we investigate the impact of such a unilateral policy in our two-country economy of the previous section. Analytically, country A's ban of $c$-electricity is treated as a sequence of small reductions in its $c$-electricity output. ${ }^{9}$ Appendix B contains the associated comparative statics and the results are summarized in

Proposition 1 Suppose the initial equilibrium of the two-country economy is characterized by a mix of c-and g-electricity, and country A unilaterally phases out the generation of electricity from coal, while the emissions cap remains unchanged. If the convexity of function $K^{c}$ is sufficiently weak, the associated comparative-static effects are as presented in Table 1 .

According to Proposition 1, the readjustments on the markets for permits and electricity create various asymmetric changes and inefficiencies. Figure 2 is useful for understanding the economic drivers of the reallocation. The solid curves are the same as in Fig. 1, so that the intersection point $\mathcal{S}_{0}$ illustrates the initial symmetric equilibrium with prices $\left(p_{0}, q_{0}\right)$ in both panels of Fig. 2. It is characterized by $y_{h 0}:=y_{h i 0}=S^{h}\left(p_{0}, q_{0}\right)>0$ for $h=c, g$,

\footnotetext{
8 The European Green Deal of the European Commission (2019) acknowledges the need for effective carbon pricing, but that will not be easy to accomplish, given the poor pricing record of the past (within and across countries).

9 More specifically, country A's ban of coal is considered as a concatenation of infinitely many marginal reductions $\mathrm{d} y_{c A}<0$ of its $c$-electricity output. As long as the sign of a comparative static effect remains unchanged, the associated displacement effect holds, not only for a marginal out-put reduction, but also for the transition towards a full ban of coal.
} 


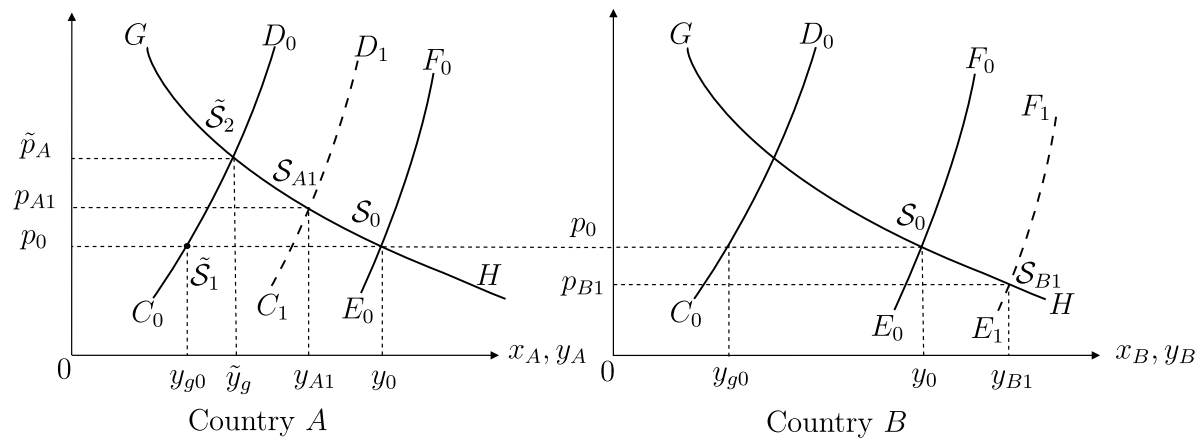

Fig. 2 Readjustments in electricity markets after country A's unilateral ban of coal (Scenario 1)

$i=A, B, D\left(p_{0}\right)=x_{0}=y_{0}:=y_{c 0}+y_{g 0}$ and $\bar{e}_{0}=2\left[v_{c} y_{c 0}+v_{g} y_{g 0}\right]$. Next we decompose the transition from the initial equilibrium to the new one of all markets after the implementation of the phase-out policy, by means of Fig. 2 in three successive steps.

(i) Suppose first that the prices $\left(p_{0}, q_{0}\right)$ remain unchanged after the ban of $c$-electricity in $A$. Then, the electricity market equilibrium in $B$ is still given by point $\mathcal{S}_{0}$ in the right panel of Fig. 2. However, in $A$ the ban generates excess demand for electricity that is illustrated by the move from $\mathcal{S}_{0}$ to $\tilde{\mathcal{S}}_{1}$ in the left panel of Fig. 2 . Since $v_{c}>v_{g}$, it obviously creates an excess supply of permits, $v_{c} y_{c 0}+2 v_{g} y_{g 0}<2 v_{c} y_{c 0}+2 v_{g} y_{g 0}=\bar{e}_{0}$.

(ii) Next, we keep the prices $q_{0}$ and $p_{B}=p_{0}$ constant and let $p_{A}$ rise to that level $\tilde{p}_{A}>p_{0}$ which clears $A$ 's electricity market, $\tilde{y}_{g}:=S^{g}\left(\tilde{p}_{A}, q_{0}\right)=D\left(\tilde{p}_{A}\right)<y_{0}$. This step corresponds to a move from $\tilde{\mathcal{S}}_{1}$ to $\tilde{\mathcal{S}}_{2}$ in the left panel of Fig. 2 . The electricity markets in $A$ and $B$ are now in equilibrium, and it follows from $y_{g 0}<\tilde{y}_{g}<y_{0}$ and $v_{c}>v_{g}$ that the permit market has excess supply, $v_{c} y_{c 0}+v_{g} y_{g 0}+v_{g} \tilde{y}_{g}<2 v_{c} y_{c 0}+2 v_{g} y_{g 0}=\bar{e}_{0}$.

(iii) In the last step, we start from the electricity market equilibria $\tilde{\mathcal{S}}_{2}$ (left panel) and $\mathcal{S}_{0}$ (right panel) and seek to clear the permit market through increasing the electricity production, and with it the emissions, under the condition that the electricity markets remain in equilibrium. To satisfy this condition we need to simultaneously reduce the prices of permits and electricity in $A$ and $B$. Ceteris paribus, the reduction of $p$ reduces the supply of electricity, but a reduction of $q$ increases it, and we choose a suitable combination of both reductions, such that a new electricity market equilibrium is attained with a larger equilibrium quantity of electricity.

In country $B$, a reduction of $q$ shifts the curve of total electricity supply $E_{0} F_{0}$ to the right, and the new equilibrium in $B$ 's electricity market $\mathcal{S}_{B 1}$ is characterized by $y_{B 1}>y_{0}$ and $p_{B 1}<p_{0}$. Interestingly, due to $v_{c}>v_{g}$ the reduction in $q$ increases the competitiveness of $c$ - compared to $g$-electricity, such that country $B$ 's $g$-electricity declines, $y_{g B 1}<y_{g 0}$, and its $c$-electricity expands, $y_{c B 1}>y_{c 0}$ - as shown in Table 1 . Due to the increase in $B$ 's $c$-electricity, the net reduction of $c$-electricity is smaller than the reduction of $c$-electricity through $A$ 's ban of coal.

The decline of the permit price $q$ that has been shown to be crucial for the impact in $B$ of $A$ 's phase out of coal distorts $A$ 's electricity market as well. In Fig. 2, it shifts the supply curve $C_{0} D_{0}$ to the right as illustrated by the dashed curve $C_{1} D_{1}$. The new electricity market equilibrium is $\left(p_{A 1}, y_{A 1}\right)$ at point $\mathcal{S}_{A 1}$ satisfying $p_{A 1}>p_{0}$ and $\tilde{y}_{g}<y_{A 1}<y_{0}$. The comparative-static analysis does not exclude that $p_{A 1}<p_{0}$ and $y_{A 1}>y_{0}$, but the conditions for either case are complex and unfortunately uninformative. We conjecture that the more 
relevant case is that the equilibrium electricity supply $y_{A 1}$ satisfies $y_{A 1}<y_{0}$ as depicted in Fig. 2. ${ }^{10}$

Summing up the third step, we move from $\tilde{\mathcal{S}}_{2}$ in $A$ and from $\mathcal{S}_{0}$ in $B$, down the electricity demand curves until we reach prices $q_{1}, p_{A 1}$ and $p_{B 1}$, thus satisfying the three equilibrium conditions $D\left(p_{A 1}\right)=S^{g}\left(p_{A 1}, q_{1}\right), \quad D\left(p_{B 1}\right)=S^{c}\left(p_{B 1}, q_{1}\right)+S^{g}\left(p_{B 1}, q_{1}\right) \quad$ and $v_{g} S^{g}\left(p_{A 1}, q_{1}\right)+v_{c} S^{c}\left(p_{B 1}, q_{1}\right)+v_{g} S^{g}\left(p_{B 1}, q_{1}\right)=\bar{e}_{0}$. In line with Table 1 , we have demonstrated that $q_{1}<q_{0}, p_{A 1}<\tilde{p}_{A}, p_{B 1}<p_{0}$, and $y_{B 1}>y_{0}$, but it remains unclear whether $y_{A 1}<y_{0}$, as shown in Fig. 2, or $y_{A 1} \geq y_{0}$.

The allocative displacement effects listed in Table 1 exhibit the remarkable feature that while country $A$ phases out the generation of $c$-electricity, country $B$ increases the generation of $c$-electricity, $S^{c}\left(p_{B 1}, q_{1}\right)>y_{c 0}$, which makes the net reduction of $c$-electricity in the two-country economy smaller than the amount $y_{c 0}$ that country $A$ phased out. Country $A$ 's phase-out policy generates a waterbed effect of emissions, since each country released $\bar{e}_{0} / 2$ emissions before the phase-out, but afterwards, country $A$ 's emissions are smaller than country $B$ 's. Since the emissions cap remains unchanged by assumption, each country's change in consumption welfare equals the change in its total welfare. It therefore follows from Table 1 that country $A$ 's unilateral phase-out policy reduces its own welfare and increases that of country $B$. Even worse, country $A$ 's loss is greater than country $B$ 's welfare gain, because the emissions cap is no longer implemented cost-effectively after the unilateral phase-out of coal.

The unilateral ban of coal can be interpreted as a policy that drives a wedge between the permit prices for $c$ - and $g$-electricity in country $A$. Formally, the permit price $q_{1}$ is uniform across countries and types of electricity after country $A$ 's phase-out of coal. However, suppose $A$ does not ban coal by 'command and control', as assumed so far, but imposes on its $c$-electricity generating firms a tax in addition to the permit price $q$, and $A$ chooses the tax rate, say $t_{c A}$, so high that the combined rate $q+t_{c A}$ renders $A$ 's $c$-electricity production unprofitable. Thus, the impact of $A$ 's selective and overlapping tax policy is the same as that of the command-and-control approach discussed above. We conclude that the policy of Scenario 1 not only creates the electricity price distortion $p_{A 1} \neq p_{B 1}$, as shown above, but also implies a permit (shadow) price distortion $q_{1} \neq q_{1}+t_{c A}$. The raison d'être of an ETS is to establish a uniform emissions price needed to secure cost-effectiveness, by equalizing the marginal abatement costs of all firms covered by the ETS. The 'market-based' unilateral ban of coal that we have outlined here creates differentiated permit prices and thus demonstrates that unilateral policies of phasing out coal, be it 'market-based' or via 'command and control', perverts the concept of an ETS by eliminating the unique advantage it is designed to offer, namely cost-effective abatement of emissions. ${ }^{11}$

\footnotetext{
${ }_{10}$ See also our comments at the end of Appendix B. In addition, Eichner and Pethig (2019b) carried out an empirical calibration in which $p_{A 1}>p_{0}$ and $y_{A 1}<y_{0}$ results.

11 The UK raised a tax on emissions covered by the EU-ETS and doubled its carbon price support in 2015 to 18
}

$$
\frac{£}{t \mathrm{CO}_{2}}
$$

on top of the (low) EU permit price (Agora Energiewende and Sandbag 2017, p. 22). The result that the generation of $c$-electricity decreased by $44 \mathrm{TWh}$ and the generation of $g$-electricity increased by $45 \mathrm{TWh}$ may be considered desirable, but it comes with a welfare loss due to non-uniform carbon pricing. 
Summing up, the unilaterally acting country $A$ punishes itself by suffering a welfare loss without achieving any reduction in aggregate emissions and climate damage. In addition, country $B$ is granted a welfare gain without any pro-climate contribution of its own. The clear message is that unilateral phase-out policies are neither desirable nor necessary for fighting climate change when an ETS already exists and the emissions cap is kept constant. The intention to ban the dirtiest electricity first may be good, but proponents of that strategy misjudge the perverse allocative displacement effects created by emissions-reducing national measures within the institutional framework of an ETS encompassing more than one country.

The strong asymmetric displacement effects in Scenario 1 are obviously driven by the unilaterality of the phase-out policy. To assess them from a different perspective, we now compare Scenario 1 with the policy of banning coal in both countries simultaneously. We prove in Appendix C

Proposition 2 Suppose the initial equilibrium of the economy is characterized by a mix of $c$ - and g-electricity, and both countries phase out the generation of electricity from coal while leaving the emissions cap unchanged. In each country, the associated comparativestatic effects are listed in Table 2.

Since the displacement effects of a full ban of coal in Table 2 are symmetric, they can be illustrated in a diagram such as Fig. 3 that exhibits the electricity market for one of the countries only. As in Fig. 2, we explain the move from the initial market equilibria to the new equilibria in three steps. Starting from the initial equilibrium point $\mathcal{S}_{0}$, we leave the prices $p_{0}$ and $q_{0}$ unchanged, and thus move from $\mathcal{S}_{0}$ to point $\tilde{\mathcal{S}}_{1}$. Both electricity markets have excess demand and the permit market excess supply. Second, we keep $q_{0}$ fixed and allow the electricity prices to clear the electricity market in each country. We thus move from $\tilde{\mathcal{S}}_{1}$ to point $\tilde{\mathcal{S}}_{2}$. Since $\tilde{y}_{2}<y_{0}$ and $v_{c}>v_{g}$, the permit market still has excess supply. Finally, we close the demand gap for permits by increasing the electricity supply under the condition that the electricity markets remain in equilibrium. That is, we start

Table 2 Allocative impact of both countries' ban of coal

\begin{tabular}{llllll}
\hline & $\mathrm{d} y_{g}$ & $\mathrm{~d} x=\mathrm{d} y$ & $\mathrm{~d} p$ & $\mathrm{~d} q$ & $\mathrm{~d} u$ \\
\hline $\mathrm{d} \bar{y}_{c}<0$ & + & + & - & - & - \\
\hline
\end{tabular}

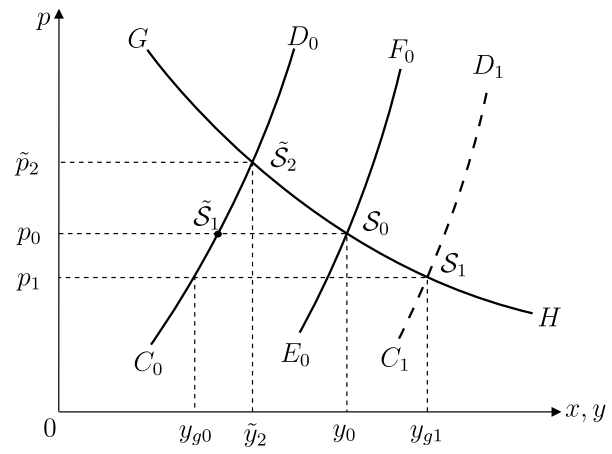

Fig. 3 Phase-out of coal in both countries 
from the equilibrium point $\tilde{\mathcal{S}}_{2}$ and move down the demand curve $G H$ to a new electricity market equilibrium at point $\mathcal{S}_{1}$ that satisfies $D\left(p_{i 1}\right)=S^{g}\left(p_{i 1}, q_{1}\right)$ for $i=A, B$, and $2 v_{g} S^{g}\left(p_{i 1}, q_{1}\right)=\bar{e}_{0}$ with $p_{A 1}=p_{B 1}=p_{1}<p_{0}$. From $2 v_{g} y_{0}<v_{g} y_{g 0}+v_{c} y_{c 0}$ it follows that $y_{g A 1}=y_{g B 1}=y_{g 1}>y_{0}$.

A comparison of the unilateral with the multilateral phase-out of coal exhibits common features but also crucial differences. In both cases, aggregate consumption welfare decreases, but both countries lose when coal is banned totally, while $B$ gains when coal is banned by $A$ only. In the event of total phase-out, the prices of permits and electricity decline, which constitutes a climate policy failure, since an effective policy would require the opposite price signals. In that respect, the unilateral ban performs only slightly better, insofar as it is likely that A's electricity price increases. Note finally, that in Table 1, the countries' changes of welfare and electricity consumption exhibit the same sign, whereas in the case of a total ban, electricity consumption rises and welfare declines in both countries.

\section{Extensions}

The comparison of the coal ban in both countries with the unilateral ban in the previous section has highlighted the strong asymmetric impact of the latter. In Sect. 4, we extend the insights into the effects of a unilateral ban of coal by modifying the analytical framework of Scenario 1 in two different ways. Section 4.1 relaxes the assumption of Scenario 1 that the emissions cap remains unchanged; it considers a policy that consists of a combination of unilateral coal phase-out and moderate tightening of the emissions cap (Scenario 2). Section 4.2 investigates how the outcomes of Scenarios 1 and 2 vary when we replace the national electricity markets in these policy scenarios with an international market for electricity.

\subsection{Unilateral Coal Phase-Out Combined with Tightening the Emissions Cap (Scenario 2)}

We showed above that the unilateral phase-out of coal decreases the permit price, which is clearly inconsistent with an effective mitigation strategy. While policymakers are reluctant to adopt phase-out policies that lead to increasing prices for electricity and permits, they are also under pressure from pro-climate-policy groups to avoid declining prices. Therefore, they may be willing to combine the unilateral phase-out policy with a moderate emissions-cap tightening. Specifically, the country acting unilaterally may combine its unilateral phase-policy with a reduction in the emissions cap by the amount of permits it purchased to cover the generation of $c$-electricity before the phase-out of coal (Scenario 2). This policy scenario is inspired by the recent revision of the EU ETS Directive (Directive EU 2018/410) that came into force in 2018 and will apply for the period 2021-2030. The revised EU Directive 2018/410 (L 76/5) stipulates that recognizing "... the interaction between climate policies at Union and national level, Member States should have the possibility of cancelling allowances from their auction volume in the event of closures of electricity-generation capacity in their territory."

Making use of the option to cancel permits amounts to cutting the overall EU missions cap. However, such 'bottom up' emissions-cap reductions need to be distinguished from 'top down' reductions of the cap that are also projected and agreed upon in the EU. 
The latter reduce emissions cost-effectively, as is well known and demonstrated at the end of Sect. 2. In Scenario 2 we investigate how the distortions of the unilateral phaseout policy in Scenario 1 are modified when a unilaterally acting country makes use of the provision of the EU Directive to cancel permits.

Conceptually, Scenario 2 can be decomposed into two parts. In the first part, country $A$ unilaterally phases out coal as in Scenario 1, and in the second part the emissions cap is tightened, which yields a benefit in the form of reduced climate damage. Since that benefit is the same for both countries (due to the additivity of the welfare function (7)), we restrict our attention to changes in consumption welfare.

In Scenario 2 that we now analyze, country $A$ complements its unilateral phase-out policy (Scenario 1) by cutting back the initial emissions cap from $\bar{e}_{0}$ to $\bar{e}_{1} \equiv \bar{e}_{0}-v_{c} \bar{y}_{c 0}$, where $\bar{y}_{c 0}$ is its generation of $c$-electricity before phasing out coal. The comparative statics of a marginal reduction in the generation of $c$-electricity, $\mathrm{d} \bar{y}_{c A}<0$, combined with a marginal reduction of the emissions cap, $\mathrm{d} \bar{e}=v_{c} \mathrm{~d} \bar{y}_{c A}<0$, is carried out in Appendix D. We summarize the results in

Proposition 3 Suppose the initial equilibrium of the two-country economy is characterized by a mix of c-and g-electricity, country A unilaterally phases out the generation of electricity from coal, and cancels its emission allowances formerly used for the generation of c-electricity. If the convexity of function $K^{c}$ is sufficiently weak, the associated comparative-static effects are as presented in Table 3.

Analogous to our procedure in Scenario 1, we explain the allocative displacement effects on the markets for permits and electricity with reference to Fig. 2. The first two steps of the decomposition procedure are the same as in Scenario 1 and we thus reach the electricity market equilibria at points $\mathcal{S}_{0}$ (right panel) and $\tilde{\mathcal{S}}_{2}$ (left panel) of Fig. 2. When the electricity markets are in these equilibria and the permit price is still constant at $q_{0}$, the permit market has excess supply in Scenario 1, $v_{c} y_{c 0}+v_{g}\left(y_{g 0}+\tilde{y}_{g}\right)<\bar{e}_{0}$, because $y_{g 0}<\tilde{y}_{g}<y_{0}$ and $v_{c}>v_{g}$, but excess demand in Scenario 2, $v_{c} y_{c 0}+v_{g}\left(y_{g 0}+\tilde{y}_{g}\right)>\bar{e}_{1}:=\bar{e}_{0}-v_{c} y_{c 0}$. Thus, the third and last step is to depart from the equilibrium points $\tilde{\mathcal{S}}_{2}$ and $\mathcal{S}_{0}$ and restore the permit-market equilibrium by reducing the generation of electricity while keeping the electricity markets in equilibrium. This is accomplished by choosing the prices $q_{1}>q_{0}, p_{A 1}>\tilde{p}_{A}$ and $p_{B 1}>p_{0}$ such that $D\left(p_{A 1}\right)=S^{g}\left(p_{A 1}, q_{1}\right)<\tilde{y}_{g}<y_{0}, D\left(p_{B 1}\right)=S^{c}\left(p_{B 1}, q_{1}\right)+S^{g}\left(p_{B 1}, q_{1}\right)$ and $v_{g} S^{g}\left(p_{A 1}, q_{1}\right)+v_{c} S^{c}\left(p_{B 1}, q_{1}\right)+v_{g} S^{g}\left(p_{B 1}, q_{1}\right)=\bar{e}_{1}$.

After the phase-out of coal in Scenario 2, all prices are higher than in Scenario 1 and higher than before the ban. This qualifies Scenario 2 as an effective policy for fighting climate change. In Scenario 2, A's emissions are smaller than $B$ 's, and in both countries they are smaller than before the coal ban. In country $A$, the loss of consumption welfare is more severe in Scenario 2 than in 1, because $A$ 's emissions decrease more strongly in 2 than in 1. While $\mathrm{d} u_{A}-\mathrm{d} u_{B}<0$ in Scenario 1, the sign of that difference is unclear in Scenario 2.

Table 3 Allocative impact of country $A$ 's unilateral ban of coal (Scenario 2)

\begin{tabular}{lllllll}
\hline & & $\mathrm{d} y_{g A}$ & $\mathrm{~d} x_{A}=\mathrm{d} y_{A}$ & $\mathrm{~d} p_{A}$ & $\mathrm{~d} q$ & $\mathrm{~d} u_{A}$ \\
\hline $\mathrm{d} \bar{y}_{c A}<0$ & & + & - & + & + & - \\
& $\mathrm{d} y_{c B}$ & $\mathrm{~d} y_{g B}$ & $\mathrm{~d} x_{B}=\mathrm{d} x_{B}$ & $\mathrm{~d} p_{B}$ & $\mathrm{~d} q$ & $\mathrm{~d} u_{B}$ \\
$\mathrm{~d} \bar{y}_{c A}<0$ & - & + & - & + & + & - \\
\hline
\end{tabular}


It is also worth noting that all comparative-static effects other than $\mathrm{d} q$ exhibit opposing signs for $A$ and $B$ in Table 1, but the same signs in Table 3. This observation suggests that the difference between the countries' welfare changes is smaller in Scenario 2 than in 1 , although it is plausible that $B$ is still better off than $A$ in Scenario 2.

\subsection{International Trade in Electricity}

So far, we have assumed that electricity is not traded internationally. Above, we referred to the EU-ETS where some transboundary trade in electricity takes place, although the crossborder infrastructure is (still) inappropriate and price convergence is partial (European Commission (2017)). We now replace the assumption of no trade by the polar opposite assumption to see how international trade modifies the effects of the unilateral phase-out policies of the Scenarios 1 and 2.

\subsubsection{Unilateral Coal Phase-Out and International Trade in Electricity (Scenario 1 with trade)}

In this section, we investigate the unilateral phase-out policy that differs from Scenario 1 only in that we replace the national markets for electricity with an international electricity market. For convenience of notation we refer to that policy scenario as Scenario 1 with trade. In Appendix E, we performed the comparative statics of Scenario 1 with trade and summarize the results in

Proposition 4 Suppose the initial equilibrium of the two-country economy with international trade in electricity is characterized by a mix of c-and g-electricity, and country A unilaterally phases out the generation of electricity from coal, while the emissions cap remains unchanged. Then, the associated comparative-static effects are as presented in Table 4.

In several steps we explain the transition of the initial prices $\left(p_{0}, q_{0}\right)$ to the new equilibrium prices $\left(p_{1}, q_{1}\right)$ in Scenario 1 with trade.

(i) With free trade in electricity, the initial state of the economy is the same as in all previous scenarios without trade, since the countries are assumed to be identical. The policy impact is decomposed as follows. We set $y_{c A}=0$, keep $\left(p_{0}, q_{0}\right)$ fixed and obtain an excess supply of permits and an excess demand in the international market for electricity: $S^{c}\left(p_{0}, q_{0}\right)+2 S^{g}\left(p_{0}, q_{0}\right)<2 D\left(p_{0}\right)$ and $e_{0}:=v_{c} S^{c}\left(p_{0}, q_{0}\right)+2 v_{g} S^{g}\left(p_{0}, q_{0}\right)<\bar{e}_{0}$. Accordingly, the current positions on the international electricity market are point $\tilde{\mathcal{S}}_{1}$ (country $A$ ) and point $\mathcal{S}_{0}$ (country $B$ ) in Fig. 3 .

(ii) In order to clear the electricity market, we leave $p_{0}$ unchanged and choose the permit price $\tilde{q}<q_{0}$ that yields $S^{c}\left(p_{0}, \tilde{q}\right)+2 S^{g}\left(p_{0}, \tilde{q}\right)=2 D\left(p_{0}\right)$. From $S_{q}^{h}<0$ it

Table 4 Allocative impact of Scenario 1 with international trade in electricity

\begin{tabular}{lllllll}
\hline & & $\mathrm{d} y_{g A}$ & $\mathrm{~d} x_{A}=\mathrm{d} y_{A}$ & $\mathrm{~d} p$ & $\mathrm{~d} q$ & $\mathrm{~d} u_{A}$ \\
\hline $\mathrm{d} \bar{y}_{c A}<0$ & & + & + & - & - & $?$ \\
& $\mathrm{~d} y_{c B}$ & $\mathrm{~d} y_{g B}$ & $\mathrm{~d} x_{B}=\mathrm{d} y_{B}$ & $\mathrm{~d} p$ & $\mathrm{~d} q$ & $\mathrm{~d} u_{B}$ \\
$\mathrm{~d} \bar{y}_{c A}<0$ & + & + & + & - & - & $?$ \\
\hline
\end{tabular}


follows that $S^{h}\left(p_{0}, \tilde{q}\right)>S^{h}\left(p_{0}, q_{0}\right)$ and therefore $\tilde{e}:=v_{c} S^{c}\left(p_{0}, \tilde{q}\right)+2 v_{g} S^{g}\left(p_{0}, \tilde{q}\right)>e_{0}$. But since $e_{0}<\bar{e}_{0}$ the sign of $\tilde{e}-\bar{e}_{0}$ is unclear. We conclude from $S^{c}\left(p_{0}, \tilde{q}\right)+2 S^{g}\left(p_{0}, \tilde{q}\right)=2 S^{c}\left(p_{0}, q_{0}\right)+2 S^{g}\left(p_{0}, q_{0}\right)=2 D\left(p_{0}\right)$ and $S^{g}\left(p_{0}, \tilde{q}\right)>S^{g}\left(p_{0}, q_{0}\right)$ that $S^{c}\left(p_{0}, \tilde{q}\right)<2 S^{c}\left(p_{0}, q_{0}\right)$, which yields $\tilde{e}<\bar{e}_{0}$ in view of $v_{c}>v_{g}$.

(iii) Thus, we need to clear the permit market while keeping the electricity market in equilibrium. This can be done by choosing suitable prices $q_{1}<\tilde{q}<q_{0}$ and $p_{1}<p_{0}$.

After the phase-out, the permits initially used by country $A$ for the generation of $c$-electricity are relocated as follows. Each country buys a share of the idle permits to increase the generation of $g$-electricity, and country $B$ uses the remaining permits to increase the generation of $c$-electricity $\left(y_{C B 1}>y_{c 0}\right)$. The quantity $y_{B 1}$ is larger than $y_{0}$ not only because $y_{g B 1}>y_{g 0}$, but also because $y_{c B 1}>y_{c 0}$. Hence, the net reduction of $c$-electricity in the twocountry economy is $y_{c 0}-\left(y_{c B 1}-y_{c 0}\right)$, which is positive but less than the $c$-electricity $y_{c 0}$ phased out by country $A$.

Country $B$ 's total electricity supply $y_{B 1}$ exceeds $y_{A 1}$ by $\Delta y_{B}=y_{c B 1}+y_{g B 1}-y_{g A 1}=y_{c B 1}>0$. Since, after the phase-out, the demand for electricity, $D\left(p_{1}\right)$, is the same in both countries, country $B$ exports - and country $A$ imports $-\frac{1}{2} \Delta y_{B}$ units of electricity. Since both countries generate the same amount of $g$-electricity, country $A$ 's electricity import can be interpreted to some extent as replacing its former $c$-electricity generation by an import of $c$-electricity. The counterpart of the changes in the supplies of and demands for electricity caused by the phase-out are changes in the purchase of permits. Specifically, country $A$ buys $\Delta e_{A}=\left|v_{c} y_{c 0}-v_{g}\left(y_{g A 1}-y_{g 0}\right)\right|$ permits less after the phase-out than before, and country $B$ increases its purchase of permits by $\Delta e_{A}$. Therefore, the crossborder trade of electricity implies a waterbed effect of permits and emissions. Put differently, country A's unilateral phase-out policy reduces domestic emissions significantly, but does so at the expense of a leakage rate of 100 percent.

The common feature of Scenarios 1 without and with transboundary trade in electricity is an aggregate welfare loss. We conjecture, however, that the loss is smaller in Scenario 1 with trade, because of the standard 'gains from trade'. While in Scenario 1 the consumption welfare in $A$ declines and that in $B$ rises, the sign of the changes in $A$ 's and $B$ 's consumption welfare is ambiguous in Scenario 1 with trade. As equations (E25) and (E26) in Appendix E show, the ambiguity arises from partial effects of cross-border electricity trade with opposing signs. Our conjecture is that country $B$ is better off than country $A$, as in Scenario 1 without trade, but that the difference in welfare changes is smaller. The observation that in Table 4 the direction of change of the variables $y_{g i}, y_{i}$ and $p_{i}, i=A, B$, is the same across countries but is different in Table 1, suggests that the international trade shifts a share of country $A$ 's welfare loss in Scenario 1 to country $B$ in Scenario 1 with trade.

\subsubsection{Unilateral Coal Phase-Out Combined with Tightening the Emissions Cap and International Trade in Electricity (Scenario 2 with Trade)}

The comparative statics of Scenario 2 with trade is carried out in Appendix F. We list the results in

Proposition 5 Suppose the initial equilibrium of the two-country economy with an international electricity market is characterized by a mix of c-and g-electricity, country A unilaterally phases out the generation of electricity from coal and cancels its emission allowances formerly used for the generation of c-electricity. Then, the associated comparative-static effects are as presented in Table 5. 
Table 5 Allocative impact of Scenario 2 with trade

\begin{tabular}{lllllll}
\hline & & $\mathrm{d} y_{g A}$ & $\mathrm{~d} x_{A}=\mathrm{d} y_{A}$ & $\mathrm{~d} p$ & $\mathrm{~d} q$ & $\mathrm{~d} u_{A}$ \\
\hline $\mathrm{d} \bar{y}_{c A}<0$ & & + & - & + & + & $?$ \\
& $\mathrm{~d} y_{c B}$ & $\mathrm{~d} y_{g B}$ & $\mathrm{~d} x_{B}=\mathrm{d} y_{B}$ & $\mathrm{~d} p$ & $\mathrm{~d} q$ & $\mathrm{~d} u_{B}$ \\
$\mathrm{~d} \bar{y}_{c A}<0$ & - & + & - & + & + & $?$ \\
\hline
\end{tabular}

We decompose the allocative displacement effects on the markets for permits and electricity listed in Table 5 as follows. First, we keep the initial equilibrium prices $\left(p_{0}, q_{0}\right)$ unchanged after country $A$ has phased out the $c$-electricity and reduced the emissions cap to level $\bar{e}_{1}:=\bar{e}_{0}-v_{c} y_{c 0}$. That creates an excess demand on the international electricity market, $S^{c}\left(p_{0}, q_{0}\right)+2 S^{g}\left(p_{0}, q_{0}\right)<2 D\left(p_{0}\right)$, and the permit market is in equilibrium, $v_{c} S^{c}\left(p_{0}, q_{0}\right)+2 v_{g} S^{g}\left(p_{0}, q_{0}\right)=\bar{e}_{1}$. We then choose an electricity price $p_{1}>p_{0}$ and a permit price $q_{1}>q_{0}$ such that the electricity market equilibrium is restored and total emissions remain the same. On the electricity market, these new prices reduce the demand, and due to $v_{c}>v_{g}$, they increase total supply by curbing the generation of $c$-electricity in $B$, and increasing the supply of $g$-electricity in $A$ and $B$ by more than the reduction of $c$-electricity. In this way it is possible to attain a new electricity-market equilibrium while changing total emissions.

The common feature of Scenarios 2 with trade (Proposition 5) and Scenario 1 with trade (Proposition 4) is that the associated comparative statics do not yield a clear sign for the change in the countries' consumption welfare. The ambiguity in Scenario 2 with trade is less expected than in Scenario 1 with trade, because the emissions cap is smaller in 2 with trade than in 1 with trade. The smaller cap reduces the capacity of producing electricity in the twocountry economy. In Scenario 1 with trade, the prices of electricity and permits are smaller, and in Scenario 2 with trade, they are higher than in the absence of A's phase-out policy, and the generation of electricity increases in Scenario 1 with trade, but decreases in 2 with trade. Comparing the comparative statics of the Scenarios 2 with and without trade reveals that both countries' consumption welfare decreases in Scenario 2 (Proposition 4) but not necessarily in Scenario 2 with trade (Proposition 5). We take this as indicating that the international trade in electricity dampens the adverse effects of unilateral phase-out policies.

\section{Concluding Remarks}

We consider a group of countries, such as the EU, with a joint ETS covering all installations generating electricity by means of natural gas or coal. The ETS countries commit to national emissions-reduction goals and may apply a 'command-and-control' policy of phasing out their generation of coal-based electricity in order to achieve these goals. This paper analyzes the interaction of the ETS with such phase-out policies and specifies the resulting displacement effects, inefficiencies and welfare effects.

We show that if an ETS country unilaterally phases out the generation of coal-based electricity, when the emissions cap is given, that country suffers a welfare loss and makes the other countries better off. Furthermore, the decline in the permit price signals that the climate policy is relaxed rather than tightened. There are climate activists and policymakers who advocate the phase-out of coal via command and control, arguing that banning the dirtiest electricity as soon as possible is the right thing to do. 
Unfortunately, what they consider common sense is in fact a failure to understand that good intentions yield perverse effects in this case.

The basic economic rationale for the inefficiency created by the interference of phaseout policies with an ETS is straightforward. The raison d'être of an ETS is the uniform emissions price that secures cost-effectiveness by equalizing the marginal abatement costs of all firms covered by the ETS. As an implication, in an international ETS such as the EU ETS, the only efficient phase-out-of-coal policy is to successively tighten the emissions cap until generating $c$-electricity becomes unprofitable in all ETS countries. Forced phase-out by command and control, be it joint or unilateral, is necessarily associated with an aggregate welfare loss. The reason for the inefficiency of forced phaseout is that it implies divergent (shadow) permit prices. Put differently, the interference of the phase-out policy with an ETS is equivalent to applying a tax regime of differentiated tax rates on emissions from coal-based and gas-based electricity. Cost-effectiveness is violated even if there is no waterbed effect of emissions - as in the case of countries that are symmetric and phase out coal jointly. The upshot is that phasing out the generation of coal-based electricity via regulation perverts the concept of an ETS by eliminating the unique advantage an ETS is designed to offer, namely cost-effective abatement induced by a uniform carbon price. If the country doing the phasing-out uses the recent option of the EU ETS Directive (Directive EU 2018/410) to tighten the emissions cap by canceling the permits formerly used for emissions from $c$-electricity, the policy is still distortive and reduces the consumption welfare in both countries. At any rate, the permit price rises rather than declines, as it does without the canceling of permits. A rising permit price is the right signal for an effective climate policy.

The contribution of the paper is a conceptual and rigorous analysis in a model that is simple enough to yield precise results and has enough structure to map some features of the energy and climate policies in the EU that are relevant for the issue at hand. Although the reduction in complexity comes with the benefit of transparency and a clear focus on essentials, we are aware that the analytical framework contains various crude simplifications for reasons of tractability. The price we pay for attaining informative analytical results is that we had to abstract from some empirically relevant aspects of coal-phase-out regulation.

Burning fossil fuels causes local pollution that appears to be more severe in the case of burning coal than gas. In order to see how the consideration of local pollution would change our results, observe that the local pollution damage decreases in $A$ but increases in $B$, if country $A$ phases out coal. As an implication, the welfare loss of country $A$ and the welfare gain of country $B$ are smaller than derived in our scenarios without local pollution.

Since many countries have significantly stepped up the generation of electricity from renewables in recent years, the electricity market(s) and the permit market are not as tightly connected in practice as in our analysis without renewables. ${ }^{12}$ How the supply of renewables reacts to unilateral phase-out policies then depends on the prevailing support schemes for renewables, and on deliberate changes in such support. Unless renewables-based electricity is promoted by feed-in tariffs (which decouples it from the electricity market), an increase [decrease] in the electricity price, as derived in our Tables 1, 3 and 5, would tend

\footnotetext{
12 The interaction between the permit market and the electricity market(s) with electricity generated from fossil and renewable resources is analyzed in Eichner and Pethig (2019a). However, that study considers homogeneous fossil energy resources and hence obviously cannot deal with phase-out-of-coal policies.
} 
to incentivize [disincentivize] the generation of electricity from renewables. An increasing [decreasing] electricity price would reduce [increase] the pressure to step up the generation of electricity from gas in order to compensate for the loss of coal-based electricity. These responses of the supply of electricity from renewables tend to soften changes in the electricity price in either direction and thus smoothen the readjustment of markets after the phase-out of coal and lower the adjustment costs.

Finally, our analysis obviously lacks important intertemporal features such as endogenous production capacities, climate-friendly technical change, a tightening of the emissions cap over time, and borrowing and banking of permits. The integration of these items into an analysis of the interaction of an ETS with phase-out policies is an agenda for future research.

\section{Appendix 1: Derivations and Assumption}

Derivation of (2): Differentiating $p_{i}-K_{i}^{h}-q v_{h}=0$ we obtain

$$
\mathrm{d} p_{i}-K_{y_{i} y_{i}}^{h} \mathrm{~d} y_{h i}-v_{h} \mathrm{~d} q=0 .
$$

From (A1) we infer

$$
S_{p_{i}}^{h} \equiv \frac{\mathrm{d} y_{h i}}{\mathrm{~d} p_{i}}=\frac{1}{K_{y_{i} y_{i}}^{h}}>0, \quad S_{q}^{h} \equiv \frac{\mathrm{d} y_{h i}}{\mathrm{~d} q}=-\frac{E_{y}^{h}}{K_{y_{i} y_{i}}^{h}}<0 .
$$

Derivation of $\frac{\mathrm{d} p}{\mathrm{~d} \bar{e}}<0$ : Consider the symmetric equilibrium ${ }^{13}$

$$
\begin{gathered}
p=P(x), \\
p=q v_{g}+K_{y}^{g}, \\
p=q v_{c}+K_{y}^{c}, \\
x=y_{c}+y_{g}, \\
\bar{e}=2 v_{g} y_{g}+2 v_{c} y_{c}, \\
u=\int_{0}^{x} P(z) \mathrm{d} z-K^{c}\left(y_{c}\right)-K^{g}\left(y_{g}\right) .
\end{gathered}
$$

Total differentiation of (A3)-(A7) leads to

$$
\mathrm{d} p=P^{\prime} \mathrm{d} x,
$$

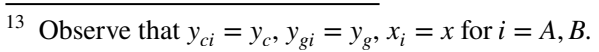




$$
\begin{gathered}
\mathrm{d} p=v_{g} \mathrm{~d} q+K_{y y}^{g} \mathrm{~d} y_{g}, \\
\mathrm{~d} p=v_{c} \mathrm{~d} q+K_{y y}^{c} \mathrm{~d} y_{c}, \\
\mathrm{~d} y_{c}+\mathrm{d} y_{g}=\mathrm{d} x, \\
2 v_{g} \mathrm{~d} y_{g}+2 v_{c} \mathrm{~d} y_{c}=\mathrm{d} \bar{e} .
\end{gathered}
$$

Inserting

$$
\mathrm{d} y_{c}=\frac{\mathrm{d} \bar{e}}{2 v_{c}}-\frac{v_{g}}{v_{c}} \mathrm{~d} y_{g}
$$

from (A13) in (A12) we obtain

$$
\mathrm{d} x=\frac{\mathrm{d} \bar{e}}{2 v_{c}}+\left(\frac{v_{c}-v_{g}}{v_{c}}\right) \mathrm{d} y_{g} .
$$

Combining (A10) and (A11) results in

$$
\frac{v_{c}-v_{g}}{v_{c} v_{g}} \mathrm{~d} p=\frac{K_{y y}^{g}}{v_{g}} \mathrm{~d} y_{g}-\frac{K_{y y}^{c}}{v_{c}} \mathrm{~d} y_{c} .
$$

Taking advantage of (A14) in (A16) we obtain

$$
\frac{v_{c}\left(v_{c}-v_{g}\right)}{v_{g}^{2} K_{y y}^{c}+v_{c}^{2} K_{y y}^{g}} \mathrm{~d} p+\frac{v_{g} K_{y y}^{c}}{2\left(v_{g}^{2} K_{y y}^{c}+v_{c}^{2} K_{y y}^{g}\right)} \mathrm{d} \bar{e}=\mathrm{d} y_{g} .
$$

Next, we insert (A9) in (A15) and solve for $d y_{g}$ which yields

$$
\mathrm{d} y_{g}=\frac{v_{c}}{P^{\prime}\left(v_{c}-v_{g}\right)} \mathrm{d} p-\frac{1}{2\left(v_{c}-v_{g}\right)} \mathrm{d} \bar{e} .
$$

Combining (A17) and (A18) we obtain

$$
\mathrm{d} p=\frac{P^{\prime}\left(v_{c} K_{y y}^{g}+v_{g} K_{y y}^{c}\right)}{2\left[v_{c}^{2} K_{y y}^{g}-P^{\prime}\left(v_{c}-v_{g}\right)^{2}+v_{g}^{2} K_{y y}^{c}\right]} \mathrm{d} \bar{e} .
$$

From (A19) we infer

$$
\frac{\mathrm{d} p}{\mathrm{~d} \bar{e}}<0 .
$$

Proof of $\mathrm{d} y_{c}>\mathrm{d} y_{g}$. From (A10) and (A11) it follows that 


$$
\begin{aligned}
\mathrm{d} y_{c} \gtreqless \mathrm{d} y_{g} & \Longleftrightarrow\left(\frac{1}{K_{y y}^{c}}-\frac{1}{K_{y y}^{g}}\right) \mathrm{d} p \gtreqless\left(\frac{v_{c}}{K_{y y}^{c}}-\frac{v_{g}}{K_{y y}^{g}}\right) \mathrm{d} q \\
& \Longleftrightarrow K_{y y}^{g}-K_{y y}^{c} \lesseqgtr\left(v_{c} K_{y y}^{g}-v_{g} K_{y y}^{c}\right) \frac{\mathrm{d} q}{\mathrm{~d} p} .
\end{aligned}
$$

We know that $\mathrm{d} y_{c}+\mathrm{d} y_{g}>0$ (if $\mathrm{d} \bar{e}>0$ ). Combined with $\mathrm{d} y_{h}=\frac{1}{K_{y y}^{h}}\left(\mathrm{~d} p-v_{h} \mathrm{~d} q\right.$ ) this inequality yields, after some rearrangement of terms,

$$
\mathrm{d} p>v_{g} \frac{\frac{v_{c}}{v_{g}} K_{y y}^{g}+K_{y y}^{c}}{K_{y y}^{c}+K_{y y}^{g}} \mathrm{~d} q \quad \text { and hence } \quad \mathrm{d} p>v_{g} \mathrm{~d} q \quad \text { or } \quad \frac{\mathrm{d} q}{\mathrm{~d} p}>\frac{1}{v_{g}} .
$$

Finally, we consider $\frac{\mathrm{d} q}{\mathrm{~d} p}>\frac{1}{v_{g}}$ in $\left(v_{c} K_{y y}^{g}-v_{g} K_{y y}^{c}\right) \frac{\mathrm{d} q}{\mathrm{~d} p}$ from (A21) and get

$$
\left(v_{c} K_{y y}^{g}-v_{g} K_{y y}^{c}\right) \frac{\mathrm{d} q}{\mathrm{~d} p}>\frac{v_{c} K_{y y}^{g}-v_{g} K_{y y}^{c}}{v_{g}}=\frac{v_{c}}{v_{g}} K_{y y}^{g}-K_{y y}^{c}>K_{y y}^{g}-K_{y y}^{c} .
$$

(A23) combined with (A21) proves that $\mathrm{d} y_{c}>\mathrm{d} y_{g}$.

\section{Appendix B: Unilateral Phase-Out of Coal with National Electricity Markets and Constant Emissions (Scenario 1)}

The associated equilibrium is characterized by the equations

$$
\begin{gathered}
p_{i}=P\left(x_{i}\right) \quad i=A, B, \\
p_{i}=v_{g} q+K_{y_{i}}^{g} \quad i=A, B, \\
p_{B}=v_{c} q+K_{y_{B}}^{c}, \\
x_{i}=y_{c i}+y_{g i} \quad i=A, B, \\
\bar{e}=v_{g} y_{g A}+v_{c} y_{c A}+v_{g} y_{g B}+v_{c} y_{c B}, \\
u_{i}=\int_{0}^{x_{i}} P(z) \mathrm{d} z-K^{c}\left(y_{c i}\right)-K^{g}\left(y_{g i}\right) . \\
y_{c A}=\bar{y}_{c A} .
\end{gathered}
$$

In the sequel, we assume ${ }^{14} K_{y y}^{c}=0$. Total differentiation of (B1)-(B7) leads to

$$
\mathrm{d} p_{i}=P_{i}^{\prime} \mathrm{d} x_{i} \quad i=A, B
$$

$\overline{14}$ The results of Appendix B and D also hold as long as $K_{y y}^{c}$ is sufficiently small. 


$$
\begin{gathered}
\mathrm{d} p_{i}=v_{g} \mathrm{~d} q+K_{y_{i} y_{i}}^{g} \mathrm{~d} y_{g i} \quad i=A, B, \\
\mathrm{~d} p_{B}=v_{c} \mathrm{~d} q, \\
\mathrm{~d} x_{A}=\mathrm{d} \bar{y}_{c A}+\mathrm{d} y_{g A}, \\
\mathrm{~d} x_{B}=\mathrm{d} y_{c B}+\mathrm{d} y_{g B}, \\
0=v_{g} \mathrm{~d} y_{g A}+v_{c} \mathrm{~d} \bar{y}_{c A}+v_{c} \mathrm{~d} y_{c B}+v_{g} \mathrm{~d} y_{g B}, \\
\mathrm{~d} u_{A}=p_{A} \mathrm{~d} x_{A}-K_{y_{A}}^{c} \mathrm{~d} \bar{y}_{c A}-K_{y_{A}}^{g} \mathrm{~d} y_{g A}, \\
\mathrm{~d} u_{B}=p_{B} \mathrm{~d} x_{B}-K_{y_{B}}^{c} \mathrm{~d} y_{c B}-K_{y_{B}}^{g} \mathrm{~d} y_{g B} .
\end{gathered}
$$

Combining (B9), (B10) and (B13) yields

$$
\begin{gathered}
\mathrm{d} y_{g A}=\frac{v_{c} \mathrm{~d} p_{A}-v_{g} \mathrm{~d} p_{B}}{v_{c} K_{y_{A} y_{A}}^{g}}, \quad \mathrm{~d} y_{g B}=\frac{\left(v_{c}-v_{g}\right) \mathrm{d} p_{B}}{v_{c} K_{y_{B} y_{B}}^{g}}, \quad \mathrm{~d} q=\frac{\mathrm{d} p_{B}}{v_{c}}, \\
\mathrm{~d} y_{c B}=-\frac{v_{c} v_{g} K_{y_{B} y_{B}}^{g} \mathrm{~d} p_{A}+\left[v_{g}\left(v_{c}-v_{g}\right) K_{y_{A} y_{A}}^{g}-v_{g}^{2} K_{y_{B} y_{B}}^{g}\right] \mathrm{d} p_{B}}{v_{c}^{2} K_{y_{A} y_{A}}^{g} K_{y_{B} y_{B}}^{g}} \\
-\frac{v_{c}^{2} K_{y_{A} y_{A}}^{g} K_{y_{B} y_{B}}^{g} \mathrm{~d} \bar{y}_{c A}}{v_{c}^{2} K_{y_{A} y_{A}}^{g} K_{y_{B} y_{B}}^{g}} .
\end{gathered}
$$

Combining (B8), (B11), (B12), (B16) and (B17) we obtain

$$
\begin{gathered}
\frac{\mathrm{d} p_{A}}{\mathrm{~d} \bar{y}_{c A}}=\frac{P_{A}^{\prime}\left[\left(-P_{B}^{\prime}\right)\left[\left(v_{c}-v_{g}\right)\left(\left(v_{c}-v_{g}\right) K_{y_{A} y_{A}}^{g}-v_{g} K_{y_{B} y_{B}}^{g}\right)+v_{c}^{2} K_{y_{A} y_{A}}^{g} K_{y_{B} y_{B}}^{g}\right]\right.}{Z}, \\
\frac{\mathrm{d} p_{B}}{\mathrm{~d} \bar{y}_{c A}^{s}}=-\frac{P_{B}^{\prime} v_{c} K_{y_{B} y_{B}}^{g}\left[v_{c} K_{y_{A} y_{A}}^{g}-P_{A}^{\prime}\left(v_{c}-v_{g}\right)\right]}{Z}>0,
\end{gathered}
$$

where

$$
\begin{aligned}
Z:= & v_{c}^{2} K_{y_{A} y_{A}}^{g} K_{y_{B} y_{B}}^{g}-P_{A}^{\prime}\left[v_{c}^{2} K_{y_{B} y_{B}}^{g}-P_{B}^{\prime}\left(v_{c}-v_{g}\right)^{2}\right] \\
& -P_{B}^{\prime}\left[v_{g}^{2} K_{y_{B} y_{B}}^{g}+\left(v_{c}-v_{g}\right)^{2} K_{y_{A} y_{A}}^{g}\right]>0 .
\end{aligned}
$$

Inserting (B18) and (B19) into (B16)-(B17) results in

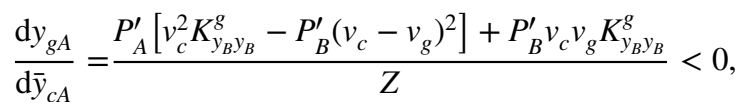




$$
\begin{gathered}
\frac{\mathrm{d} y_{g B}}{\mathrm{~d} \bar{y}_{c A}}=-\frac{P_{B}^{\prime}\left(v_{c}-v_{g}\right)\left[v_{c} K_{y_{A} y_{A}}^{g}-P_{A}^{\prime}\left(v_{c}-v_{g}\right)\right]}{Z}>0, \\
\frac{\mathrm{d} y_{c B}}{\mathrm{~d} \bar{y}_{c A}}=-\frac{\left[v_{c} K_{y_{A} y_{A}}^{g}-P_{A}^{\prime}\left(v_{c}-v_{g}\right)\right]\left[v_{c} K_{y_{B} y_{B}}^{g}-P_{B}^{\prime}\left(v_{c}-v_{g}\right)\right]}{Z}<0
\end{gathered}
$$

and

$$
\begin{gathered}
v_{g} \frac{\mathrm{d} y_{g B}}{\mathrm{~d} \bar{y}_{c A}}+v_{c} \frac{\mathrm{d} y_{c B}}{\mathrm{~d} \bar{y}_{c A}}=-v_{g} \frac{\mathrm{d} y_{g A}}{\mathrm{~d} \bar{y}_{c A}}-v_{c} \\
=-\frac{\left[v_{c} K_{y_{A} y_{A}}^{g}-P_{A}^{\prime}\left(v_{c}-v_{g}\right)\right]\left[v_{c}^{2} K_{y_{B} y_{B}}^{g}-P_{B}^{\prime}\left(v_{c}-v_{g}\right)^{2}\right]}{Z}<0 .
\end{gathered}
$$

Next, accounting for (B2), (B3) and $p_{A}=K_{y_{A}}^{c}+q v_{c}+\tau$ (where $\tau$ is the shadow price of capping coal-based electricity) the consumption welfare changes are given by

$$
\begin{gathered}
\frac{\mathrm{d} u_{A}}{\mathrm{~d} \bar{y}_{c A}}=\underbrace{q\left(v_{c}+v_{g} \frac{\mathrm{d} y_{g A}}{\mathrm{~d} \bar{y}_{c A}}\right)}_{+}+\tau>0, \\
\frac{\mathrm{d} u_{B}}{\mathrm{~d} \bar{y}_{c A}}=q\left(v_{c} \frac{\mathrm{d} y_{c B}}{\mathrm{~d} \bar{y}_{c A}}+v_{g} \frac{\mathrm{d} y_{g B}}{\mathrm{~d} \bar{y}_{c A}}\right)<0, \\
\frac{\mathrm{d} u_{A}+\mathrm{d} u_{B}}{\mathrm{~d} \bar{y}_{c A}}=q\left[v_{c}\left(1+\frac{\mathrm{d} y_{c B}}{\mathrm{~d} \bar{y}_{c A}}\right)+\left(v_{g} \frac{\mathrm{d} y_{g A}}{\mathrm{~d} \bar{y}_{c A}}+v_{g} \frac{\mathrm{d} y_{g B}}{\mathrm{~d} \bar{y}_{c A}}\right)\right]+\tau=\tau>0 .
\end{gathered}
$$

Finally, we further investigate $\frac{\mathrm{d} p_{A}}{\mathrm{~d} \bar{y}_{C A}}$ from (B18). For quadratic $K^{g}$-functions we obtain

$$
v_{c}>2 v_{g} \Longrightarrow \frac{\mathrm{d} p_{A}}{\mathrm{~d} \bar{y}_{c A}}<0 .
$$

The results are summarized in Proposition 1.

It is worth mentioning that in economies with linear demand functions, linear $K^{c}$ -functions and quadratic $K^{g}$-functions we were not able to prove the existence of economies satisfying $y_{g A}>0, y_{g B}>0, y_{c B}>0$ and $\frac{\mathrm{d} p_{A}}{\mathrm{~d} \bar{y}_{c A}}>0$.

\section{Appendix C: Joint Phase-Out of Coal}

Consider the symmetric equilibrium (A3)-(A8) and assume that $\bar{y}_{c A}=\bar{y}_{c B} \equiv \bar{y}_{c}$ is chosen by the government of country $i=A, B$. Then total differentiation of (A3)-(A8) leads to

$$
\begin{gathered}
\mathrm{d} p=P^{\prime} \mathrm{d} x, \\
\mathrm{~d} p=v_{g} \mathrm{~d} q+K_{y y}^{g} \mathrm{~d} y_{g},
\end{gathered}
$$




$$
\begin{gathered}
\mathrm{d} \bar{y}_{c}+\mathrm{d} y_{g}=\mathrm{d} x, \\
2 v_{g} \mathrm{~d} y_{g}^{s}+2 v_{c} \mathrm{~d} \bar{y}_{c}^{s}=0, \\
p \mathrm{~d} x-K_{y}^{c} \mathrm{~d} \bar{y}_{c}-K_{y}^{g} \mathrm{~d} y_{g}=\mathrm{d} u .
\end{gathered}
$$

From (C4) we get

$$
\mathrm{d} y_{g}=-\frac{v_{c}}{v_{g}} \mathrm{~d} \bar{y}_{c}
$$

Inserting (C6) in (C3) we obtain

$$
\mathrm{d} x=\frac{v_{g}-v_{c}}{v_{g}} \mathrm{~d} \bar{y}_{c} .
$$

Making use of (C7) in (C1) we get

$$
-\frac{P^{\prime}\left(v_{c}-v_{g}\right)}{v_{g}} \mathrm{~d} y_{c}=\mathrm{d} p .
$$

Finally, accounting for (C3), (A4) and $p-K_{y}^{c}=v_{c} q+\tau$ (where $\tau>0$ is the shadow price of capping coal-based electricity) in (C5) the welfare change is given by

$$
\frac{\mathrm{d} u}{\mathrm{~d} \bar{y}_{c}}=q\left(v_{c}+v_{g} \frac{\mathrm{d} y_{g}}{\mathrm{~d} \bar{y}_{c}}\right)+\tau .
$$

Taking advantage of (C6) establishes

$$
\frac{\mathrm{d} u}{\mathrm{~d} \bar{y}_{c}}=\tau>0 .
$$

The results are summarized in Proposition 2.

\section{Appendix D: Unilateral Phase-Out of Coal with National Electricity Markets and Cancelling Emission Allowances (Scenario 2)}

The equilibrium of the model is characterized by the equations (B1)-(B4), (B6)-(B7) and

$$
\bar{e}-v_{c} y_{c A}=v_{g} y_{g A}+v_{c} y_{c A}+v_{g} y_{g B}+v_{c} y_{c B},
$$

Total differentiation of these equations yields (B8)-(B12), (B14)-(B15) and

$$
v_{g} \mathrm{~d} y_{g A}+v_{c} \mathrm{~d} y_{c B}+v_{g} \mathrm{~d} y_{g B}=0 .
$$

Solving (B8)-(B12) and (D2) we obtain

$$
\frac{\mathrm{d} p_{A}}{\mathrm{~d} \bar{y}_{c A}}=\frac{P_{A}^{\prime}\left[v_{c}^{2} K_{y_{A} y_{A}}^{g} K_{y_{B} y_{B}}^{g}-P_{B}^{\prime}\left(\left(v_{c}-v_{g}\right)^{2} K_{y_{A} y_{A}}^{g}+v_{g}^{2} K_{y_{B} y_{B}}^{g}\right)\right]}{Z}<0,
$$




$$
\begin{gathered}
\frac{\mathrm{d} p_{B}}{\mathrm{~d} \bar{y}_{c A}}=-\frac{P_{A}^{\prime} P_{B}^{\prime} v_{c} v_{g} K_{y_{B} y_{B}}^{g}}{Z}<0, \\
\frac{\mathrm{d} y_{g A}}{\mathrm{~d} \bar{y}_{c A}}=\frac{P_{A}^{\prime}\left[v_{c}^{2} K_{y_{B} y_{B}}^{g}-P_{B}^{\prime}\left(v_{c}-v_{g}\right)^{2}\right]}{Z}<0, \\
\frac{\mathrm{d} y_{g B}}{\mathrm{~d} \bar{y}_{c A}}=-\frac{P_{A}^{\prime} P_{B}^{\prime}\left(v_{c}-v_{g}\right) v_{g}}{Z}<0, \\
\frac{\mathrm{d} y_{c B}}{\mathrm{~d} \bar{y}_{c A}}=-\frac{P_{A}^{\prime} v_{g}\left[v_{c} K_{y_{B} y_{B}}^{g}-P_{B}^{\prime}\left(v_{c}-v_{g}\right)\right]}{Z}>0
\end{gathered}
$$

and

$$
\begin{gathered}
v_{c} \frac{\mathrm{d} y_{c B}}{\mathrm{~d} \bar{y}_{c A}}+v_{g} \frac{\mathrm{d} y_{g B}}{\mathrm{~d} \bar{y}_{c A}}=-v_{g} \frac{\mathrm{d} y_{g A}}{\mathrm{~d} \bar{y}_{c A}}=-\frac{P_{A}^{\prime} v_{g}\left[v_{c}^{2} K_{y_{B} y_{B}}^{g}-P_{B}^{\prime}\left(v_{c}-v_{g}\right)^{2}\right]}{Z}>0, \\
v_{c}+v_{g} \frac{\mathrm{d} y_{g A}}{\mathrm{~d} \bar{y}_{c A}}= \\
=\frac{v_{c}^{3} K_{y_{A} y_{A}}^{g} K_{y_{B} y_{B}}^{g}-P_{A}^{\prime}\left(v_{c}-v_{g}\right)\left[v_{c}^{2} K_{y_{B} y_{B}}^{g}-P_{B}^{\prime}\left(v_{c}-v_{g}\right)^{2}\right]}{Z} \\
-\frac{P_{B}^{\prime} v_{c}\left[\left(v_{c}-v_{g}\right)^{2} K_{y_{A} y_{A}}^{g}+v_{g}^{2} K_{y_{B} y_{B}}^{g}\right]}{Z}>0 .
\end{gathered}
$$

Finally, the consumption welfare changes are given by

$$
\begin{gathered}
\frac{\mathrm{d} u_{A}}{\mathrm{~d} \bar{y}_{c A}}=q\left(v_{c}+v_{g} \frac{\mathrm{d} y_{g A}}{\mathrm{~d} \bar{y}_{c A}}\right)+\tau>0, \\
\frac{\mathrm{d} u_{B}}{\mathrm{~d} \bar{y}_{c A}}=q\left(v_{c} \frac{\mathrm{d} y_{c B}}{\mathrm{~d} \bar{y}_{c A}}+v_{g} \frac{\mathrm{d} y_{g B}}{\mathrm{~d} \bar{y}_{c A}}\right)=-q v_{g} \frac{d y_{g B}}{\mathrm{~d} \bar{y}_{c A}}>0, \\
\frac{\mathrm{d} u_{A}+\mathrm{d} u_{B}}{\mathrm{~d} \bar{y}_{c A}}=q\left[v_{c}\left(1+\frac{\mathrm{d} y_{c B}}{\mathrm{~d} \bar{y}_{c A}}\right)+v_{g} \frac{\mathrm{d} y_{g A}}{\mathrm{~d} \bar{y}_{c A}}+v_{g} \frac{\mathrm{d} y_{g B}}{\mathrm{~d} \bar{y}_{c A}}\right]+\tau=q v_{c}+\tau>0 .
\end{gathered}
$$

The results are summarized in Proposition 3.

\section{Appendix E: Unilateral Phase-Out of Coal with International Electricity Markets and Constant Emissions (Scenario 1 with trade)}

The associated equilibrium is characterized by the equations

$$
\begin{gathered}
p=P\left(x_{i}\right) \quad i=A, B, \\
p=q v_{g}+K_{y i}^{g} \quad i=A, B,
\end{gathered}
$$




$$
\begin{gathered}
p=q v_{c}+K_{y B}^{c}, \\
x_{A}+x_{B}=y_{c A}+y_{g A}+y_{c B}+y_{g B}, \\
\bar{e}=v_{g} y_{g A}+v_{c} y_{c A}+v_{g} y_{g B}+v_{c} y_{c B}, \\
u_{i}=\int_{0}^{x_{i}} P(z) \mathrm{d} z-K^{c}\left(y_{c i}\right)-K^{g}\left(y_{g i}\right) \quad i=A, B, \\
y_{c A}=\bar{y}_{c A} .
\end{gathered}
$$

Observe that equilibria are characterized by $y_{g A}=y_{g B}$ which follows from (E2). Therefore, it holds $K_{y_{A}}^{g}=K_{y_{A}}^{g} \equiv K_{y}^{g}$ and $K_{y_{A} y_{A}}^{g}=K_{y_{B} y_{B}}^{g} \equiv K_{y y}^{g}$.

Inserting (E7) in (E1)-(E6) and total differentiation leads to

$$
\begin{gathered}
\mathrm{d} p=P_{i}^{\prime} \mathrm{d} x_{i} \quad i=A, B, \\
\mathrm{~d} p=v_{g} \mathrm{~d} q+K_{y y}^{g} \mathrm{~d} y_{g i} \quad i=A, B, \\
\mathrm{~d} p=v_{c} \mathrm{~d} q+K_{y_{B} y_{B}}^{c} \mathrm{~d} y_{c B}, \\
\mathrm{~d} x_{A}+\mathrm{d} x_{B}=\mathrm{d} \bar{y}_{c A}+\mathrm{d} y_{g A}+\mathrm{d} y_{c B}+\mathrm{d} y_{g B}, \\
0=v_{g} \mathrm{~d} y_{g A}+v_{c} \mathrm{~d} \bar{y}_{c A}+v_{c} \mathrm{~d} y_{c B}+v_{g} \mathrm{~d} y_{g B}, \\
\mathrm{~d} u_{A}=p \mathrm{~d} x_{A}-K_{y_{A}}^{c} \mathrm{~d} \bar{y}_{c A}-K_{y}^{g} \mathrm{~d} y_{g A}, \\
\mathrm{~d} u_{B}=p \mathrm{~d} x_{B}-K_{y_{B}}^{c} \mathrm{~d} y_{c B}-K_{y}^{g} \mathrm{~d} y_{g B} .
\end{gathered}
$$

From (E9), (E10) and (E2) we infer

$$
\mathrm{d} y_{g A}=\mathrm{d} y_{g B},
$$

and

$$
\mathrm{d} y_{c B}=-\frac{v_{c}-v_{g}}{v_{g} K_{y_{B} y_{B}}^{c}} \mathrm{~d} p+\frac{v_{c} K_{y y}^{g}}{v_{g} K_{y_{B} y_{B}}^{c}} \mathrm{~d} y_{g i} .
$$

Making use of (E15) in (E12) yields

$$
\mathrm{d} y_{c B}=-\mathrm{d} \bar{y}_{c A}-\frac{2 v_{g}}{v_{c}} \mathrm{~d} y_{g i} .
$$

Next, we combine (E16) and (E17) to obtain 


$$
\mathrm{d} y_{g i}=\frac{v_{c}\left(v_{c}-v_{g}\right)}{v_{c}^{2} K_{y y}^{g}+2 v_{g}^{2} K_{y_{B} y_{B}}^{c}} \mathrm{~d} p-\frac{K_{y_{B} y_{B}}^{c}}{v_{c}^{2} K_{y y}^{g}+2 v_{g}^{2} K_{y_{B} y_{B}}^{c}} \mathrm{~d} \bar{y}_{c A} .
$$

Inserting (E15), (E17) and (E18) in (E11) implies

$$
\begin{aligned}
\mathrm{d} x_{A}+\mathrm{d} x_{B} & =\frac{2\left(v_{c}-v_{g}\right)}{v_{c}} \mathrm{~d} y_{g i} \\
& =\frac{2\left(v_{c}-v_{g}\right)^{2}}{v_{c}^{2} K_{y y}^{g}+2 v_{g}^{2} K_{y_{B} y_{B}}^{c}} \mathrm{~d} p-\underbrace{\frac{2\left(v_{c}-v_{g}\right) K_{y_{B} y_{B}}^{c}}{v_{c}\left[v_{c}^{2} K_{y y}^{g}+2 v_{g}^{2} K_{\left.y_{B} y_{B}\right]}^{c}\right]}}_{=: \mu} \mathrm{d} \bar{y}_{c A}
\end{aligned}
$$

Observe that $\mu>0$.

Taking advantage of (E8) in (E19) yields

$$
\left[\frac{2\left(v_{c}-v_{g}\right)^{2}}{v_{c}^{2} K_{y y}^{g}+2 v_{g}^{2} K_{y_{B} y_{B}}^{c}}-\frac{1}{P_{A}^{\prime}}-\frac{1}{P_{B}^{\prime}}\right] \mathrm{d} p=\mu \mathrm{d} \bar{y}_{c A},
$$

which implies

$$
\frac{\mathrm{d} p}{\mathrm{~d} \bar{y}_{c A}}>0
$$

In view of (E8), (E19), (E15) and (E16) it holds

$$
\frac{\mathrm{d} x_{A}}{\mathrm{~d} \bar{y}_{c A}}<0, \quad \frac{\mathrm{d} x_{B}}{\mathrm{~d} \bar{y}_{c A}}<0, \quad \frac{\mathrm{d} y_{g A}}{\mathrm{~d} \bar{y}_{c A}}<0, \quad \frac{\mathrm{d} y_{g B}}{\mathrm{~d} \bar{y}_{c A}}<0, \quad \frac{\mathrm{d} y_{c B}}{\mathrm{~d} \bar{y}_{c A}}<0 .
$$

Finally, we consider the welfare changes in (E13) and (E14). Making use of (E11) yields

$$
\begin{aligned}
& \mathrm{d} u_{A}=\left(p-K_{y A}^{c}\right) \mathrm{d} \bar{y}_{c A}+\left(p-K_{y}^{g}\right) \mathrm{d} y_{g A}+\left(\mathrm{d} y_{c B}+\mathrm{d} y_{g B}-\mathrm{d} x_{B}\right) p, \\
& \mathrm{~d} u_{B}=\left(p-K_{y B}^{c}\right) \mathrm{d} y_{c B}+\left(p-K_{y}^{g}\right) \mathrm{d} y_{g B}+\left(\mathrm{d} \bar{y}_{c A}+\mathrm{d} y_{g A}-\mathrm{d} x_{A}\right) p .
\end{aligned}
$$

Accounting for (E2) and (E3) in (E23) and (E24) we obtain

$$
\begin{aligned}
\frac{\mathrm{d} u_{A}}{\mathrm{~d} \bar{y}_{c A}} & =\underbrace{q\left(v_{c}+v_{g} \frac{\mathrm{d} y_{g A}}{\mathrm{~d} \bar{y}_{c A}}\right)}_{+}+\tau+\underbrace{\left(\frac{\mathrm{d} y_{c B}}{\mathrm{~d} \bar{y}_{c A}}+\frac{\mathrm{d} y_{g B}}{\mathrm{~d} \bar{y}_{c A}}-\frac{\mathrm{d} x_{B}}{\mathrm{~d} \bar{y}_{c A}}\right) p}_{-}, \\
\frac{\mathrm{d} u_{B}}{\mathrm{~d} \bar{y}_{c A}} & =\underbrace{q\left(v_{c} \frac{\mathrm{d} y_{c B}}{\mathrm{~d} \bar{y}_{c A}}+v_{g} \frac{\mathrm{d} y_{g B}}{\mathrm{~d} \bar{y}_{c A}}\right)}_{-}+\underbrace{\left(1+\frac{\mathrm{d} y_{g A}}{\mathrm{~d} \bar{y}_{c A}}-\frac{\mathrm{d} x_{A}}{\mathrm{~d} \bar{y}_{c A}}\right) p,}_{+} \\
\frac{\mathrm{d} u_{A}+\mathrm{d} u_{B}}{\mathrm{~d} \bar{y}_{c A}} & =q\left[v_{c}+v_{c} \frac{\mathrm{d} y_{c B}}{\mathrm{~d} \bar{y}_{c A}}+v_{g}\left(\frac{\mathrm{d} y_{g A}}{\mathrm{~d} \bar{y}_{c A}}+\frac{\mathrm{d} y_{g B}}{\mathrm{~d} \bar{y}_{c A}}\right)\right]+\tau=\tau>0 .
\end{aligned}
$$


The signs under the last round brackets in (E25) and (E26) follow from $\mathrm{d} x_{A}=\mathrm{d} x_{B}$, $\mathrm{d} y_{g A}=\mathrm{d} y_{g B}, \frac{\mathrm{d} y_{c B}}{\mathrm{~d} \bar{y}_{c A}}<0$ and (E11).

\section{Appendix F: Unilateral Phase-Out of Coal with International Electricity Markets and Cancelling Emission Allowances (Scenario 2 with trade)}

The equilibrium of the model is characterized by (E1)-(E4), (E6)-(E7) and (D1), Total differentiation of these equations yields

$$
\begin{gathered}
\mathrm{d} p=P_{i}^{\prime} \mathrm{d} x_{i} \quad i=A, B, \\
\mathrm{~d} p=v_{g} \mathrm{~d} q+K_{y y}^{g} \mathrm{~d} y_{g i} \quad i=A, B, \\
\mathrm{~d} p=v_{c} \mathrm{~d} q+K_{y_{B} y_{B}} \mathrm{~d} y_{c B}, \\
\mathrm{~d} x_{A}+\mathrm{d} x_{B}=\mathrm{d} \bar{y}_{c A}+\mathrm{d} y_{g A}+\mathrm{d} y_{c B}+\mathrm{d} y_{g B}, \\
v_{c} \mathrm{~d} \bar{y}_{c A}=v_{g} \mathrm{~d} y_{g A}+v_{c} \mathrm{~d} \bar{y}_{c A}+v_{c} \mathrm{~d} y_{c B}+v_{g} \mathrm{~d} y_{g B}, \\
\mathrm{~d} u_{A}=p \mathrm{~d} x_{A}-K_{y_{A}}^{c} \mathrm{~d} \bar{y}_{c A}-K_{y}^{g} \mathrm{~d} y_{g A}, \\
\mathrm{~d} u_{B}=p \mathrm{~d} x_{B}-K_{y_{B}}^{c} \mathrm{~d} y_{c B}-K_{y}^{g} \mathrm{~d} y_{g B} .
\end{gathered}
$$

Using the same steps of rearrangement as in Appendix E we obtain

$$
\begin{gathered}
\mathrm{d} y_{g A}=\mathrm{d} y_{g B}, \\
\mathrm{~d} y_{c B}=-\frac{2 v_{g}}{v_{c}} \mathrm{~d} y_{g i}, \\
\mathrm{~d} y_{g i}=\frac{v_{c}\left(v_{c}-v_{g}\right)}{v_{c}^{2} K_{y y}^{g}+2 v_{g}^{2} K_{y_{B} y_{B}}^{c}} \mathrm{~d} p, \\
\mathrm{~d} x_{A}+\mathrm{d} x_{B}=\frac{2\left(v_{c}-v_{g}\right)^{2}}{v_{c}^{2} K_{y y}^{g}+2 v_{g}^{2} K_{y_{B} y_{B}}^{c}} \mathrm{~d} p+\mathrm{d} \bar{y}_{c A} .
\end{gathered}
$$

Combining (F1) and (F11) we get

$$
\left[\frac{2\left(v_{c}-v_{g}\right)^{2}}{v_{c}^{2} K_{y y}^{g}+2 v_{g}^{2} K_{y_{B} y_{B}}^{c}}-\frac{1}{P_{A}^{\prime}}-\frac{1}{P_{B}^{\prime}}\right] \mathrm{d} p=-\mathrm{d} \bar{y}_{c A},
$$

which implies 


$$
\frac{\mathrm{d} p}{\mathrm{~d} \bar{y}_{c A}}<0
$$

In view of (F8)-(F10) and (F13) we get

$$
\frac{\mathrm{d} x_{A}}{\mathrm{~d} \bar{y}_{c A}}>0, \quad \frac{\mathrm{d} x_{B}}{\mathrm{~d} \bar{y}_{c A}}>0, \quad \frac{\mathrm{d} y_{g A}}{\mathrm{~d} \bar{y}_{c A}}<0, \quad \frac{\mathrm{d} y_{g B}}{\mathrm{~d} \bar{y}_{c A}}<0 \quad \frac{\mathrm{d} y_{c B}}{\mathrm{~d} \bar{y}_{c A}}>0 .
$$

The consumption welfare changes are given by

$$
\begin{aligned}
& \frac{\mathrm{d} u_{A}}{\mathrm{~d} \bar{y}_{c A}}=q\left(v_{c}+v_{g} \frac{\mathrm{d} y_{g A}}{\mathrm{~d} \bar{y}_{c A}}\right)+\underbrace{\left(\frac{\mathrm{d} y_{c B}}{\mathrm{~d} \bar{y}_{c A}}+\frac{\mathrm{d} y_{g B}}{\mathrm{~d} \bar{y}_{c A}}-\frac{\mathrm{d} x_{B}}{\mathrm{~d} \bar{y}_{c A}}\right)}_{+} p+\tau, \\
& \frac{\mathrm{d} u_{B}}{\mathrm{~d} \bar{y}_{c A}}=q\left(v_{c} \frac{\mathrm{d} y_{c B}}{\mathrm{~d} \bar{y}_{c A}}+v_{g} \frac{\mathrm{d} y_{g B}}{\mathrm{~d} \bar{y}_{c A}}\right)+\left(1+\frac{\mathrm{d} y_{g A}}{\mathrm{~d} \bar{y}_{c A}}-\frac{\mathrm{d} x_{A}}{\mathrm{~d} \bar{y}_{c A}}\right) p \\
& =\underbrace{-q v_{g} \frac{\mathrm{d} y_{g A}}{\mathrm{~d} \bar{y}_{c A}}}_{+}+\underbrace{\left(1+\frac{\mathrm{d} y_{g A}}{\mathrm{~d} \bar{y}_{c A}}-\frac{\mathrm{d} x_{A}}{\mathrm{~d} \bar{y}_{c A}}\right) p}_{-}, \\
& \frac{\mathrm{d} u_{A}+\mathrm{d} u_{B}}{\mathrm{~d} \bar{y}_{c A}}=q\left[v_{c}+v_{c} \frac{\mathrm{d} y_{c B}}{\mathrm{~d} \bar{y}_{c A}}+v_{g}\left(\frac{\mathrm{d} y_{g A}}{\mathrm{~d} \bar{y}_{c A}}+\frac{\mathrm{d} y_{g B}}{\mathrm{~d} \bar{y}_{c A}}\right)\right]+\tau=q v_{c}+\tau>0 .
\end{aligned}
$$

The results are summarized in Proposition 5.

Funding Open Access funding enabled and organized by Projekt DEAL.

Open Access This article is licensed under a Creative Commons Attribution 4.0 International License, which permits use, sharing, adaptation, distribution and reproduction in any medium or format, as long as you give appropriate credit to the original author(s) and the source, provide a link to the Creative Commons licence, and indicate if changes were made. The images or other third party material in this article are included in the article's Creative Commons licence, unless indicated otherwise in a credit line to the material. If material is not included in the article's Creative Commons licence and your intended use is not permitted by statutory regulation or exceeds the permitted use, you will need to obtain permission directly from the copyright holder. To view a copy of this licence, visit http://creativecommons.org/licenses/by/4.0/.

\section{References}

Agora Energiewende, Sandbag (2020) The European power sector in 2019. State of affairs and review of current developments

Agora Energiewende, Sandbag (2017) Energy transition in the power sector in Europe: state of affairs in 2016. Review on the developments in 2016 and outlook on 2017

Chakravorty U, Moreaux M, Tidball M (2008) Ordering the extraction of polluting nonrenewable resources. Am Econ Rev 98:1128-1144

Coulomb R, Henriet F (2018) The grey paradox: how fossil-fuel owners can benefit from carbon taxation. J Environ Econ Manag 87:206-223

Cropper ML, Oates WE (1992) Environmental economics: a survey. J Econ Lit 30:675-740

Daubanes JX, Henriet F, Schubert K (2021) Unilateral $\mathrm{CO}_{2}$ reduction policy with more than one carbon energy source. J Assoc Environ Resour Econ 8:543-575 
Directive (EU) 2018/410 of the European Parliament to and of the council of 14 March 2018 amending Directive 2003/87/EC to enhance cost-effective emission reductions and low-carbon investments, and Decision (EU) $2015 / 1814$

Eichner T, Pethig R (2019b) Phase-out of 'coal to power' in an ETS, CESifo Working Paper 7554

Eichner T, Pethig R (2019a) EU-type carbon regulation and the waterbed effect of green energy promotion. Energy Econ 80:656-679

European Commission (2019) The European Green Deal, Com (2019) 640 final

European Commission (2017) Quarterly Report on European Electricity Markets, DG Energy, Volume 10 issue 1

Fell H, Kaffine DT, Novan K (2019) Emissions, transmissions, and the environmental value of renewable energy, CEnREP Working Paper, vol No. 19-015. Center for Environmental and Resource Economic Policy, Raleigh, NC

Fischer C, Preonas L (2010) Combining policies for renewable energy: is the whole less than the sum of its parts? Int Rev Environ Resour Econ 4:51-92

Fischer C, Salant SW (2017) Balancing the carbon budget for oil: the distributive effects of alternative policies. Eur Econ Rev 99:191-215

Garella PG, Trentinaglia MT (2019) Carbon tax, emission standard and carbon leak under price competition. Environ Resour Econ 72:941-964

Hamaguchi Y (2020) The effect of environmental tax evasion on pollution havens within the EU's dual regulation system, mimeo

Holland SP, Mansur ET, Muller N, Yates AJ (2018) Decompositions and policy consequences of an extraordinary decline in air pollution from electricity generation, NBER Working Paper No. 25339

IPCC (2018): Special report on global warming of $1.5^{\circ} \mathrm{C}$

Jarke J, Perino G (2017) Do renewable energy policies reduce carbon emissions? On caps and inter-industry leakage. J Environ Econ Manag 84:102-124

Klaushal KR, Rosendahl KE (2020) Taxing consumption to mitigate carbon leakage. Environ Resour Econ 75:151-181

McGlade C, Ekins P (2015) The geographical distribution of fossil fuels unused when limiting global warming to $2^{\circ} \mathrm{C}$. Nature 517:187-190

MacKay DJC, Stone TJ (2013) Potential greenhouse gas emissions associated with shale gas extraction and use, report

Novan K (2017) Overlapping environmental policies and the impact on pollution. J Assoc Environ Resour Econ 4:153-199

Oates W, Schwab R (1988) Economic competition among jurisdictions: efficiency enhancing or distortion inducting? J Public Econ 35:33-54

Ogawa H, Wildasin D (2009) Think locally, act locally: spillovers, spillbacks, and efficient decentralized policymaking. Am Econ Rev 99:1206-1217

Pahle M, Burtraw D, Tietjen O, Flachsland C, Edenhofer O (2019) Unilateral action under an emissions cap, paper presented at the annual meeting of the American Economic Association 2019

Perino G (2018) New phase 4 - EU ETS rules temporarily puncture waterbed. Nature Climate Change

Pittel K, Rübbelke D (2017) Thinking local but acting global? The interplay between local and global internalization of externalities. In: Buchholz W, Rübbelke D (eds) The theory of externalities and public goods. Springer, Cham

Santore R, Robison HD, Klein Y (2001) Strategic state-level environmental policy with asymmetric pollution spillovers. J Public Econ 80:199-224

Stiglitz J, Stern N (2017) Report of the High-Level commission on carbon prices

Van der Ploeg F, Withagen C (2012) Too much coal, too little oil. J Public Econ 96:62-77

Verbon HAA, Withagen C (2010) Do permit allocations matter, CESifo Working Paper 3236

Publisher's Note Springer Nature remains neutral with regard to jurisdictional claims in published maps and institutional affiliations. 